\title{
Wind-driven rain on two parallel wide buildings: field measurements and CFD
}

\section{simulations}

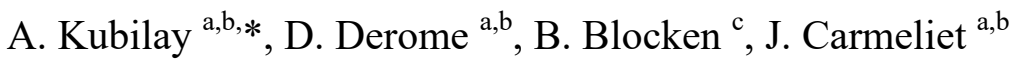

${ }^{a}$ Chair of Building Physics, Swiss Federal Institute of Technology ETHZ, Zurich, Switzerland

${ }^{b}$ Laboratory for Multiscale Studies in Building Physics, Swiss Federal Laboratories for Materials Science and Technology

(Empa), Dübendorf, Switzerland

${ }^{c}$ Building Physics and Services, Eindhoven University of Technology, Eindhoven, The Netherlands

* Corresponding author: Aytaç Kubilay, Laboratory for Multiscale Studies in Building Physics, Swiss Federal Laboratories for Materials Science and Technology (Empa), Überlandstrasse 129, CH-8600, Dübendorf, Switzerland. Tel.: +41 58765 4276; E-mail address: aytac.kubilay@empa.ch

\begin{abstract}
Most studies of wind-driven rain (WDR) reported in the literature focus either on isolated buildings or on a particular building in geometrically complex environments. There is a need for experimental and numerical studies for more generic multi-building geometries. The present study reports detailed field measurements and numerical simulations of WDR that are conducted for an idealized geometry with two parallel wide buildings with different heights, located in Dübendorf, Switzerland. The datasets of rain events and WDR measurements with high spatial and temporal resolution are made available online to download and are intended for model development and validation. Numerical simulations are performed with computational fluid dynamics (CFD) based on the 3D steady Reynolds-averaged Navier-Stokes (RANS) equations and an Eulerian multiphase (EM) model for WDR, including the turbulent dispersion of raindrops. The numerical results are validated by comparing the calculated catch ratio values and cumulative WDR amounts with data from the field measurements. The CFD simulations accurately estimate the WDR intensities at the positions of 18 WDR gauges. The average discrepancies between the numerical and experimental results are found to be $6.9 \%$ for the rain event on February 20-21, 2014 and 4.9\% for the rain event on August 2-3, 2014. In different building configurations, the influences of This document is the accepted manuscript version of the following article: Kubilay, A., Derome, D., Blocken, B., \& Carmeliet, J. (2015). Wind-driven rain on two parallel wide buildings: field measurements and CFD simulations. Journal of Wind Engineering and Industrial Aerodynamics, 146, 11-28. http://doi.org/10.1016/j.jweia.2015.07.006

This manuscript version is made available under the CC-BY-NC-ND 4.0 license http://creativecommons.org/licenses/by-nc-nd/4.0/
\end{abstract}


recirculation regions, sheltering, wind-blocking effect and acceleration of wind determine the WDR distribution on the downstream building. WDR can increase due to recirculation regions and acceleration of wind, while wind-blocking effect and sheltering decrease WDR.

Keywords: Wind-driven rain, Field measurements, Computational fluid dynamics (CFD), Eulerian multiphase model, Turbulent dispersion, Validation

\section{Introduction}

Wind-driven rain (WDR) is the type of rain which has a horizontal velocity vector due to the effect of wind flow occurring at the same time. WDR is one of the most important moisture sources that influence the hygrothermal performance and the durability of building facades. It can lead to several undesired phenomena in building physics such as frost damage at exterior wall surfaces $[1,2]$, erosion of building materials $[3,4]$, moisture induced salt migration $[2,5]$, discoloration by efflorescence [2], surface soiling [6,7] and mold growth at interior wall surfaces [8]. WDR intensity is used as a boundary condition in studies for moisture transport in the building envelope, film runoff and cooling effect due to evaporation. In such studies, the WDR intensity is often considered uniform across large parts of the facade. This may lead to discrepancies as in reality the WDR intensity is far from uniform across building facades, even in the simplest case of isolated buildings. In multi-building environments, the wind flow patterns are influenced by groups of buildings and are even more complex. Buildings may influence the WDR exposure of each other due to their sizes and wind-recirculation regions between the buildings [9]. The impinging WDR intensity is governed by a wide range of parameters, such as building geometry, environment topography, position on the building facade, wind speed, wind direction, rainfall intensity and raindrop-size distribution [10]. Methods to accurately estimate the WDR intensity on building facades should, therefore, take into account these influencing parameters. The studies by Blocken and Carmeliet [11, 12], Blocken et al. [13] and Blocken [14] provide extensive reviews of different methods used in WDR research in building physics.

Semi-empirical methods are fast and easy to use but they only give approximations of the WDR intensity and they cannot provide detailed information. Furthermore, the semi-empirical methods are unable to reliably take into account all the effects that influence the WDR intensity $[9,15]$, especially in a multi-building environment [16]. Therefore, semi-empirical methods are generally only suitable for isolated buildings in simple configurations, or for preliminary analysis. 
Computational fluid dynamics (CFD) simulations, on the other hand, have the advantage of providing detailed spatial and temporal WDR distributions in complex building geometries [10, 17-20]. Furthermore, CFD simulations can give detailed information on the rain drop impact speed and impact angle on the facade, which can later be used to determine the droplet physics after impact, such as bouncing, splashing, spreading and film forming. A steady-state numerical simulation technique for WDR was developed by Choi [21-24] by combining the 3D steady Reynolds-averaged Navier-Stokes (RANS) equations and a Lagrangian particle tracking (LPT) model. Blocken and Carmeliet [10] extended Choi's simulation technique by adding the temporal component, allowing the determination of both the spatial and temporal distribution of WDR for transient rain events. LPT is the most commonly used method to estimate WDR intensity in the literature [7, 10, 17-20, 25-29]. Huang and Li [30] used an Eulerian Multiphase (EM) model with RANS and showed that it can give accurate results for WDR on the windward facade of an isolated low-rise building. Kubilay et al. [31] performed a validation study with the EM model on a historical building with a high-rise tower by comparing the results with existing measurement data. This study showed that the user time spent for the simulation of WDR on an isolated building decreases by at least a factor of 10 with the EM model compared to the LPT model. The EM model allows for less computational complexity and a simpler quantification of the influence of turbulent dispersion of raindrops compared to the LPT models, as well as the ability to estimate WDR on all surfaces in a complex geometry, e.g. facade details, roofs, street. The turbulent dispersion of raindrops was implemented into the EM model for the mean WDR calculations by Kubilay et al. [32]. It was shown that taking turbulent dispersion into account reduces the deviation between CFD simulations and field measurements at lower parts of a high-rise building by up to $65 \%$.

Development and validation of such numerical models require complete WDR measurement datasets, which follow strict guidelines in order to ensure their accuracy and reliability and to keep measurement errors small [15]. Up to now, field measurements of WDR focused on either isolated buildings or on a particular building in a geometrically complex environment $[3,15,17,20,33-36]$. However, for detailed model validation in geometries with more than one building, there is a need for high-resolution measurements in more generic and idealized multi-building configurations. Recently, Kubilay et al. [16] reported a dataset of field measurements in a geometry composed of a regular array of low-rise cubic buildings.

The present study reports a WDR measurement dataset with high spatial and temporal resolution for a setup consisting of two parallel wide buildings, one of which is higher. The study involves 18 WDR gauges with an acquisition resolution of about $0.025 \mathrm{~mm} /$ tip that aim to measure and compare the spatial and temporal distribution of WDR intensity on the facades 
of the two buildings. Furthermore, the field measurement data are used to validate CFD simulations of WDR which are performed with an Eulerian multiphase (EM) model that takes into account the turbulent dispersion modeling of raindrops [32]. In the present paper, section 2 presents the field measurement geometry and the measured rain event data for the validation study. In section 3, the numerical model, the governing equations, the computational domain, the boundary conditions and the solver settings are described. Section 4 presents the validation study and analysis of the WDR intensity on the building models. Finally, sections 5 and 6 provide a general discussion and conclusion, respectively.

\section{Field measurements}

\subsection{Buildings and surrounding site}

The measurement setup is located on the campus of the Swiss Federal Laboratories for Materials Science and Technology (Empa) in Dübendorf in a suburban area located east of the city of Zurich, Switzerland, latitude $47^{\circ} 24^{\prime} 9^{\prime \prime}$ and longitude $8^{\circ} 36^{\prime} 50^{\prime \prime}$. The field measurements in the present study aim to study the WDR intensities on two parallel wide buildings with different heights. The schematic representation, the photograph of the measurement geometry, and the plan view of the measurement site are shown in Fig. 1. Nine cubic building models are manufactured so that the measurement setup is adjustable and can be rearranged to represent different measurement geometries. Each of the cubic building models in Fig. 1 has dimensions of $\mathrm{H} \times \mathrm{H} \times \mathrm{H}=2 \times 2 \times 2 \mathrm{~m}^{3}$. Three of the cubic building models have been placed together to form a wide lower building, i.e. building 1 , which is located in the upstream direction with respect to the predominant wind direction during rainfall. A wide higher building, i.e. building 2, composed of the remaining 6 cubic building models is located in the downstream direction. The buildings 1 and 2 are spaced $2 \mathrm{~m}$ apart. Both buildings are positioned on pavement blocks and wooden beams for protection from moisture and convenience of relocation. The total roof heights including the support beneath the buildings are $2.17 \mathrm{~m}$ for building 1 and $4.29 \mathrm{~m}$ for building 2 . The wooden beams under the buildings prevent airflow occurring underneath. The gap between the lower and upper rows of cubes on building 2 is further closed with plastic plates. In Fig. 1(a), the southwest top corners of the buildings are indicated with dots. Preliminary analysis of the local meteorological data indicates that the main wind direction, from which most WDR is obtained, is west. Therefore, the measurements of WDR are conducted on the west facades of buildings 1 and 2, indicated in grey in Fig. 1(a).

The measurement site has an open field with short grass located southwest of the setup. In west direction, the field is about $70 \mathrm{~m}$ long and, further upstream, high trees and buildings are present. In south direction, the field is about $130 \mathrm{~m}$ long and, 
further upstream, mid-rise buildings and a motorway are present. From northwest to east, there are several nearby low-rise and mid-rise buildings. The closest of them are located at about $20 \mathrm{~m}$ distance from the experimental setup to northwest and northeast.

\subsection{Measurement equipment}

The wind speed, wind direction, wind elevation, air temperature and horizontal rainfall intensity are recorded in addition to the WDR in order to provide the required data to allow analysis of the WDR intensity and to provide validation data for numerical simulations. Wind direction is the azimuth angle from north. Wind elevation is the angle of the wind velocity vector with the horizontal plane.

\subsubsection{Wind measurements}

In order to measure the approach-flow wind direction and wind speed, a meteorological mast is positioned west of the measurement site. The measurement site is located within an internal boundary layer where the approach-flow profile is still developing. Thus, the position of the mast has to be chosen as close as possible to the setup to catch the most representative approach-flow boundary layer profile. However, at the same time, its location should be outside the region influenced by the buildings themselves in order to measure the unobstructed free-field wind profile. The position of the mast is chosen to be at $6 \mathrm{~m}$ away from the buildings, as determined by preliminary CFD simulations.

The meteorological mast is equipped with a 3D ultrasonic anemometer at $8.4 \mathrm{~m}$ height, which provides information on wind speed, wind direction and wind elevation. Additionally, two cup anemometers are installed at 2.4 and $5.4 \mathrm{~m}$ heights to measure the approach-flow wind profile. The sampling rate for the anemometers is $1 \mathrm{~Hz}$. Fig. 2 shows the averaged measured wind profiles for the wind flow perpendicular to the test facades (wind from west) and for $45^{\circ}$ oblique directions (wind from northwest and southwest). The markers show the measured values, whereas the lines show the fitted curve using the neutrally stratified atmospheric boundary layer log-law profile:

$U(y)=\frac{u_{A B L}^{*}}{\kappa} \ln \left(\frac{y+y_{0}}{y_{0}}\right)$ 
where $U(y)$ denotes the mean streamwise wind speed at a height $y$ above the ground plane, $u^{*}{ }_{A B L}$ the atmospheric boundary layer (ABL) friction velocity, $\kappa$ the von Karman constant ( 0.42 in the present study) and $y_{0}$ the aerodynamic roughness length. For wind from west and southwest, $u^{*}{ }_{A B L} / U=0.24$ and $y_{0}=0.49 \mathrm{~m}$. For wind from northwest, $u^{*}{ }_{A B L} / U=0.34$ and $y_{0}=1.02 \mathrm{~m}$. Note that, as the approach flow is in reality in an internal boundary layer, the log-law assumption is a simplification. For other wind directions such as southeast, east and northeast, the buildings influence the wind-flow profile at the meteorological mast; therefore, for these wind directions, the actual approach-flow profile will not be obtained.

\subsubsection{Rain measurements}

The horizontal rainfall intensity is measured $0.4 \mathrm{~m}$ above the ground by a rain gauge positioned near the weather mast. The rain gauge has a horizontal orifice and a tipping bucket mechanism. The sampling rate for the rain gauge is $1 \mathrm{~Hz}$. The effective volume of the tipping bucket is $2.15 \mathrm{ml}$ and the rain gauge orifice is $0.02 \mathrm{~m}^{2}$, which results in a resolution of about $0.11 \mathrm{~mm} / \mathrm{tip}$.

\subsubsection{WDR measurements}

The collectors of the WDR gauges used in the present study are manufactured at Empa following the guidelines of Blocken and Carmeliet [37]. As shown in Fig. 3, they are made of aluminum with catch surfaces of ordinary glass sheets to promote runoff [37]. The collection area is $0.2 \times 0.2 \mathrm{~m}^{2}$. The collectors are connected via tubing to the tipping bucket mechanisms, which are placed inside the building models. This way, frost problems for the buckets are avoided and the evaporation from the bucket is less variable during the rain event. The tipping buckets each have an effective tipping bucket volume of about $1 \mathrm{ml}$. The resolutions of the WDR gauges are about $0.025 \mathrm{~mm} /$ tip, i.e. about 4 times higher than the horizontal rain gauge. The sampling rate for the WDR gauges is $1 \mathrm{~Hz}$. There are 18 WDR gauges in total, 2 on building 1 and 16 on building 2 . Fig. 4 shows the positions of the WDR gauges on the test facades of buildings 1 and 2 . Table 1 and Table 2 show the tipping bucket resolutions for each WDR gauge on buildings 1 and 2, respectively.

In WDR measurements, the largest sources of errors are stated to be due to adhesion water on the WDR collection area, $E_{A W}$, and the rest-water in the tipping bucket, $E_{R W},[15,35,37]$. There is always a certain amount of water adhered to the collection area and a certain amount that stays in the tipping bucket, which are not measured by the gauge and evaporate mainly during dry periods during a rain event or after a rain event. For the WDR gauges used in the present paper, spraying tests showed that the adhered amount of rain on the collector and within the tube was $0.128 \mathrm{~mm}\left(\mathrm{or} \mathrm{L} / \mathrm{m}^{2}\right)$. The rest-water 
error is related to the size of the tipping bucket. Further measurement errors related to splashing and condensation on the collector as well as wind errors due to collector are not easy to estimate. Although the adhered water remaining on the collector is estimated with spray tests, the water amount that stays in the tipping buckets during a dry period will be different for each WDR gauge. Furthermore, the time required for the evaporation of the adhered water will largely be influenced by the environmental conditions, e.g. temperature, relative humidity, wind speed. Therefore, the rain event data presented in this study are not corrected for the evaporation of water during dry periods. The error estimations will assume the total evaporation of the adhered WDR amount and the rest water during a dry period before the rain shower starts again. This way, the error estimations are very conservative and the actual error will be less than these estimations in most cases.

In order to keep the measurement errors due to evaporation as small as possible, rain events with large amounts of WDR must be selected. Furthermore, rain events with less dry periods in between the rain showers are expected to limit the errors due to evaporation of adhered droplets, as well as the rest-water error [37]. Therefore, the selection of rain events for the validation study should ensure that the related errors are small and kept at a relatively limited proportion [37]. A total of 28 rain events were measured between February 2014 and August 2014. An important aspect is the proper identification of a single rain event. In the literature, there is a wide range of criteria in defining the start and end of rain events [38]. The minimum gap between two different rain events is largely chosen based on the application. In the present study, a rain event is assumed to end if the following dry period lasts longer than $12 \mathrm{~h}$. Furthermore, rain spells shorter than $2 \mathrm{~mm} / \mathrm{h}$ were not classified as rain events. 5 of the 28 rain events measured between February 2014 and August 2014 are selected for further study retaining the events with the lowest measurement errors. The complete dataset of the selected rain events, including the ones presented in this paper, is available at the following website:

http://www.carmeliet.arch.ethz.ch/ResearchDatabase/Wind-drivenRain

The time interval for which the experimental data are provided is chosen to be 10 minutes following the guidelines by van der Hoven [39], Sumner [40] and Blocken and Carmeliet [41, 42] in order to minimize the errors related to the time resolution of meteorological datasets. Thus, the measured wind speed, wind direction and wind elevation during rain events in the dataset are presented as 10-min averaged values. Similarly, the horizontal rainfall amount and the WDR amount are 10-min summed values. 


\section{Numerical simulation}

\subsection{Governing equations}

In the present study, the wind-flow equations are solved using 3D steady Reynolds-averaged Navier-Stokes (RANS) with the renormalization group (RNG) $k-\varepsilon$ model [43]. In the Eulerian multiphase (EM) model, the rain phase is regarded as a continuum. Each rain phase corresponds to a different class of raindrop sizes. A class of raindrop size is a range of droplet diameters which show similar WDR behavior. For each rain phase, the following continuity and momentum equations are solved:

$$
\begin{aligned}
& \frac{\partial \alpha_{d}}{\partial t}+\frac{\partial \alpha_{d} \overline{u_{d, j}}}{\partial x_{j}}=0 \\
& \frac{\partial \alpha_{d} \overline{u_{d, i}}}{\partial t}+\frac{\partial \alpha_{d} \overline{u_{d, i} u_{d, j}}}{\partial x_{j}}+\frac{\partial \alpha_{d} \overline{u_{d, i}^{\prime} u_{d, j}^{\prime}}}{\partial x_{j}}=\alpha_{d} g_{i}+\alpha_{d} \frac{3 \mu_{a}}{\rho_{w} d^{2}} \frac{C_{d} \operatorname{Re}_{R}}{4}\left(\overline{u_{i}}-\overline{u_{d, i}}\right)
\end{aligned}
$$

where $d$ denotes the raindrop diameter, $\alpha_{d}$ the phase fraction of rain phase $d, u_{d, j}$ the velocity component of rain phase $d, u_{i}$ the velocity component of wind in direction $i, \rho_{w}$ the density of water, $\mu_{a}$ the dynamic viscosity of air, $g$ the gravitational acceleration, $C_{d}$ the drag coefficient. $\mathrm{Re}_{R}$ denotes the relative Reynolds number calculated using the relative velocity between the air and rain phases. The overbar denotes Reynolds averaging. In Eq. (3), the terms on the left-hand side are the transient term, the mean convective flux and the turbulent flux. The terms on the right-hand side represent the gravity and the drag forces. Turbulent dispersion of droplets is due to the turbulent motions modeled by the third term on the left-hand side. Turbulent dispersion was neglected in many earlier WDR modeling efforts $[9,10,20,22,23,27,30]$ and discrepancies of the numerical results at lower wind speed regions were mainly attributed to the neglect of turbulent dispersion. In the EM model, by defining a response coefficient, $C_{t}$, velocity fluctuations in rain phases can be related to the velocity fluctuations in wind:

$$
C_{t}^{2}=\frac{\overline{u_{d, i}^{\prime} u_{d, j}^{\prime}}}{\overline{u_{i}^{\prime} u_{j}^{\prime}}}=\frac{1}{1+\frac{t_{p}}{t_{f l}}}
$$


where $t_{p}$ denotes the particle relaxation which is the time rate of response of particle acceleration to the relative velocity between the particle and the carrier fluid. $t_{f l}$ denotes the Lagrangian fluid time scale which is the characteristic large eddy lifetime. For a more detailed description of the turbulent dispersion modeling of raindrops, the reader is referred to Kubilay et al. [32]. As the particle relaxation time gets smaller compared to the Lagrangian fluid time scale, e.g. smaller raindrops, $C_{t}$ approaches the value of 1 . In such cases, raindrops are more influenced by the fluctuations in wind velocity.

\subsection{WDR parameters}

The WDR intensity is related to the unobstructed horizontal rainfall intensity by the specific catch ratio, $\eta_{d}(d)$, and the catch ratio, $\eta$. The specific catch ratio is related to the rain phase $d$. The catch ratio is related to the entire spectrum of raindrop diameters. The quantities of the WDR parameters can be obtained after solving the governing equations in Eqs. (2-3) and by using the following relations:

$$
\begin{aligned}
& \eta_{d}(d)=\frac{R_{w d r}(d)}{R_{h}(d)}=\frac{\alpha_{d}\left|V_{n}(d)\right|}{R_{h} f_{h}\left(R_{h}, d\right)} \\
& \eta=\int_{d} f_{h}(d) \eta_{d}(d) \mathrm{d} d
\end{aligned}
$$

where $R_{w d r}$ denotes the WDR intensity, $R_{h}$ the horizontal rain intensity through the horizontal plane, $f_{h}\left(R_{h}, d\right)$ the raindropsize distribution through the horizontal plane [11] and $\left|V_{n}(d)\right|$ the velocity magnitude of the rain phase in the direction

normal to the building facade. In the present study, the raindrop-size distribution by Best [44] and the terminal velocities by Gunn and Kinzer [45] have been used.

\subsection{Computational domain}

The CFD simulations use the same building configurations as in the field measurements. Computational domains for northwest, west and southwest wind directions using the geometry for the field measurements are shown in Fig. 5. For an accurate study, the flow profiles should be horizontally homogeneous because the inlet profiles actually correspond to the measured data obtained at a location close to the building. However, several researchers [46-51] reported the occurrence of 
unintended streamwise gradients in the vertical flow profiles (or horizontal inhomogeneity) due to the inconsistencies between the inlet boundary conditions, the wall boundary conditions, the surface roughness modeling and the computational grid. If the computational domain in Fig. 5(b) is also used for oblique wind directions, the approach flow on one side accelerates more due to the unequal distances from the inlet. Thus, separate computational domains were prepared for each wind direction, so that the distances of the buildings from both inlet boundaries for oblique wind directions are equal. As a remedial measure against horizontal inhomogeneity $[46,48]$, a relatively short distance of $6 \mathrm{~m}$ is chosen. Note that this distance corresponds also to the actual distance of the meteorological mast to the building models. The remaining boundary distances from the building models satisfy the CFD best-practice guidelines stated in Tominaga et al. [52] and Franke et al. [53].

For the grid-sensitivity analysis, three structured and purely hexahedral computational grids are created. The base grid consists of 533808 cells. The coarse grid has 180936 cells whereas the fine grid has 1318912 cells. The first cell heights on the ground and at building surfaces are kept constant $(0.015 \mathrm{H}$ for ground and $0.005 \mathrm{H}$ for building surfaces) for each grid in order to keep the dimensionless wall distance $y^{+}$the same. The average $y^{+}$value is 91 on the ground and 94 on the building surfaces. The grid-sensitivity analysis was conducted by comparing the magnitude of the wind velocity along three vertical lines all in the centerplane from the ground up to a height of $2.5 \mathrm{H}$ : positioned 1) $0.05 \mathrm{H}$ upstream of building 1, 2) $0.05 \mathrm{H}$ downstream of building 1 and 3) $0.05 \mathrm{H}$ upstream of the building 2, as shown in Fig. 6. Streamwise velocity values are mostly very close to each other on different grids apart from close to the ground along line b. The vertical velocity profiles, on the other hand, show differences up to $27 \%$ between coarse and base grids and up to $8 \%$ between fine and base grids. As a result, the fine grid is chosen for the rest of the study. The fine computational grid on the buildings and on part of the ground surface is shown in Fig. 7.

\subsection{Boundary conditions}

The inlet profile of mean wind speed is given by the typical log-law expression as described in Eq. (1). The inlet profiles of the turbulent quantities $k$ and $\varepsilon$ are defined by Eqs. (7) and (8), where $I_{u}$ denotes the streamwise turbulence intensity. The turbulence intensity is taken to be $30 \%$ at $y=2 \mathrm{~m}$ height, $8 \%$ at $y=200 \mathrm{~m}$ height for southwest and west wind and $40 \%$ at $y=2 \mathrm{~m}$ height, $10 \%$ at $y=200 \mathrm{~m}$ height for northwest wind.

$k(y)=\left(I_{u} U(y)\right)^{2}$ 
$\varepsilon(y)=\frac{u_{A B L}^{*}{ }^{3}}{\kappa\left(y+y_{0}\right)}$

For wall treatment, the standard wall functions by Launder and Spalding [54] with sand-grain roughness modification [55] are used. The equivalent sand-grain roughness height, $k_{s}$, and the roughness constant, $C_{s}$, are determined by the following relation by Blocken et al. [48] which is valid for the wall function in OpenFOAM:

$k_{s}=\frac{E y_{0}}{C_{s}}$

where $E$ is an empirical constant with a value of 9.793. In the computational domain, the ground surface represents the asphalt parking lot in Fig. 1(b), for which, $k_{s}$ is taken to be $0.005 \mathrm{~m}$ and $C_{s}$ is set as 9.793 , leading to an aerodynamic roughness length $y_{0}=0.005 \mathrm{~m}$, representing a featureless land surface without any noticeable obstacles [56]. Note that the above-mentioned higher values of $y_{0}$ represent the ground surface beyond (i.e. upstream of) the computational domain. The building surfaces are assumed to be smooth $\left(k_{s}=0\right)$.

For the top boundary, constant values are set for $U, k$ and $\varepsilon$ by using fixed values from the inlet profiles at the same height as suggested by Blocken et al. [48], e.g. $U_{\text {top }}=U_{\text {inlet }}(y=30 \mathrm{~m})$. This is done in order to limit the horizontal inhomogeneity, as other top boundary conditions, such as a symmetry condition, can cause unintended streamwise gradients. Although imposing constant values does not allow fluid to enter or exit the domain, the top boundary is far enough from the buildings not to cause a problem. A constant static gauge pressure of $0 \mathrm{~Pa}$ is used at the outlet boundary. This boundary condition at the outlet implies a fully developed flow at the outlet and should not interfere with the results as long as the outlet boundary is placed away from the influence by the buildings (15H distance [53], see Fig. 5). Note that this gauge pressure is relative to reference atmospheric pressure. Symmetry conditions are applied on both sides of the domain for wind from west. For the domains for the wind from southwest and northwest, the side domains are set as inlet and/or outlet.

The volumetric ratio of rain phase $d, \alpha_{d}$, can be calculated as in Eq. (10), where $V_{t}(d)$ represents the terminal velocity of a raindrop with diameter $d$ : 


$$
\alpha_{d}=\frac{R_{h} f_{h}\left(R_{h}, d\right)}{V_{t}(d)}
$$

The value of volumetric ratio of each rain phase, $\alpha_{d}$, is imposed at the inlet and top boundaries. For the rain phase velocity, $u_{k}$, it is assumed that the boundaries are undisturbed and far away from the building in the domain. The vertical inlet rain phase velocity component is set equal to the terminal velocity for that phase. The horizontal inlet rain phase velocity components are set equal to the air phase velocity components, so that the relative velocity between wind and rain is zero at the boundary.

The boundary conditions for the rain phases at the building walls, on the ground and at the outlet are set in such way that the normal gradient of the volumetric ratio, $\partial \alpha_{d} / \partial n$, equals zero when the normal wind velocity vector is pointing out of the domain, and the values of the volumetric ratio, $\alpha_{d}$, are equal to zero when the normal wind velocity vector is pointing into the domain. With these boundary conditions, the interaction between the raindrops and the walls are not modeled and the raindrops leave the domain as soon as they hit a wall boundary, avoiding any inflow of rain phase into the domain due to possible recirculation regions.

\subsection{Solution strategy}

In the present study, the multiphase flow of air and rain phases is considered to be a dilute flow. The volumetric ratio of rain in air is usually below $1 \times 10^{-4}$ even for strong rainfall intensities [30]. The study by de Wolf [57] estimates the number of raindrops per unit volume which leads to a volume ratio of $1 \times 10^{-6}$ for a rainfall intensity of $10 \mathrm{~mm} / \mathrm{h}$ and $1 \times 10^{-4}$ for 100 $\mathrm{mm} / \mathrm{h}$. In a dilute dispersed phase flow, the average time between particle-particle collisions is larger than the time that particles need to adjust to a change in velocity. Therefore, forces such as gravity and drag, instead of collisions between raindrops, govern the raindrop motion. In the present study, the rain phase calculations are one-way coupled with the air phase, where the effect of raindrops on the wind flow is thus ignored.

The solution methodology is similar to the Choi's steady-state WDR approach [22,23] that was extended into the time domain by Blocken and Carmeliet [10, 41]. It consists of the following steps: 
a. The steady-state wind flow field around the buildings is calculated for the reference wind speed $U=1 \mathrm{~m} / \mathrm{s}$ and the reference wind directions southwest $\left(\varphi=225^{\circ}\right)$, west $\left(\varphi=270^{\circ}\right)$ and northwest $\left(\varphi=315^{\circ}\right)$. The wind-flow field for other values of reference wind speed $(U=2,3,5 \mathrm{~m} / \mathrm{s})$ are obtained by linear scaling. Such scaling is allowed for flows around sharp-edged bluff bodies, where the positions of flow separation are independent of the Reynolds number.

b. The turbulent viscosity, $v_{t}$, is scaled linearly for the reference wind speed values, $U=2,3,5 \mathrm{~m} / \mathrm{s}$. Similarly, the turbulence kinetic energy, $k$, is scaled quadratically and the turbulence dissipation rate, $\varepsilon$, is scaled cubically. For fully turbulent flow, the turbulence statistics have only a weak dependence on Reynolds number [58]. Wind-tunnel measurements by Defraeye [59] for flows around bluff bodies show limited Reynolds number dependency at Re $>10^{4}$, calculated with reference wind speed and building height.

c. The governing equations for the rain phases are solved and specific catch ratio distributions are calculated for several raindrop diameters (diameters ranging from 0.3 to $1 \mathrm{~mm}$ in steps of $0.1 \mathrm{~mm}$, from 1 to $2 \mathrm{~mm}$ in steps of $0.2 \mathrm{~mm}$ and from 2 to $6 \mathrm{~mm}$ in steps of $1 \mathrm{~mm})$.

d. Catch ratio distributions are obtained for reference horizontal rainfall intensities of $R_{h}=0,0.1,0.5,1,2,3,4,5,6,8,10$, $12,15,20,25$ and $30 \mathrm{~mm} / \mathrm{h}$ using the droplet-size distribution as input for each reference wind speed and wind direction. Note that the buildings influence the wind-flow pattern at the meteorological mast for wind directions such as southeast, east and northeast. Thus, the catch ratio values for wind directions between $\varphi=0^{\circ}-180^{\circ}$ are not calculated and assumed zero on the west facades of the buildings.

e. The calculated catch ratio values are interpolated based on the experimental data records for wind speed, wind direction and horizontal rainfall intensity at each 10-min experimental time step during a certain rain event to obtain the spatial and temporal distributions of WDR on the building facades.

\subsection{Solver settings}

OpenFOAM ${ }^{\circledR} 2.2[60]$ is used in this study as the CFD code. It is an open-source, implicit, segregated, and double precision solver. An additional solver has been implemented into the code by the authors for solving the governing equations of the rain phases. The pressure-velocity coupling for the wind-flow field solution is taken care of with the Semi-Implicit Method 
for Pressure Linked Equations (SIMPLE) algorithm. Second-order discretization schemes are used for both the convection terms and the viscous terms of the governing equations. For both the air and rain phase calculations, the simulations were terminated when all the scaled residuals reached $10^{-6}$.

\section{Results and validation of the numerical model}

\subsection{Rain event on February 20-21, 2014}

The meteorological data for the rain event on February 20-21, 2014 are shown in Fig. 8(a). The total rainfall amount at the end of the rain event is $12 \mathrm{~mm}$. The mean air temperature is $6.4{ }^{\circ} \mathrm{C}$. The rain event is composed of rain showers with several interruptions within a time frame of about 15 hours. During the initial part of the rain event the wind is mainly from southeast and later from southwest.

Fig. 9(a) and (b) show the measured and numerical catch ratio values on the west facade of building 1 at the end of the rain event. The positions of the WDR gauges are indicated by squares. The numerical values indicated next to the positions of the WDR gauges are averaged values over the area of each gauge. The deviations between numerical and experimental values are $2.1 \%$ and $2.8 \%$ for WDR gauges 1 and 2, respectively. Fig. 9(c) compares the measured and numerical cumulative WDR amounts for the gauge positions along the central axis of the test facade during the rain event. Fig. 10 compares the measured and numerical catch ratio values at the end of the rain event as well as the cumulative WDR amounts during the rain event on the west facade of building 2 . The highest catch ratio values are obtained on building 2 because of the fact that building 2 is higher. Furthermore, the gradient of catch ratio is larger on the facade of building 2 compared to building 1. For most of the rain event, the wind direction is oblique to the test facades. Hence, the contours of catch ratio, especially for building 2 in Fig. 10(b), display an asymmetrical wetting pattern with larger values on the right (southern) side of the facade. However, the surface-averaged numerical catch ratios as well as the experimental catch ratios do not show such a large difference between the two sides of the facade. The catch ratio values on building 2 are lower compared to building 1 for positions at the same height from the ground, as shown for example by the WDR gauges $1(\eta=0.14)$ and $2(\eta=0.12)$ on building 1 and the WDR gauges $9(\eta=0.10)$ and $10(\eta=0.09)$ on building 2 . For the total WDR sum at the end of the rain event, the numerical values on building 2 show average deviations of $6.3 \%$ from the experimental values at the upper half of the facade and of $9.8 \%$ at the bottom half. The average deviation along the central axis is $7.0 \%$. 
Fig. 9(c) and Fig. 10(c) show that there is a small amount of WDR measured at the beginning of the rain event. During the following few hours where the wind is mainly from southeast, there is no WDR registration by the gauges. Afterwards, there is a sharp increase in the cumulative WDR amounts. This corresponds to the meteorological conditions between 09:00 and 10:00, where the reference wind speed increases sharply and the wind direction is from west (about $270^{\circ}$ from north). Numerical model accurately predicts this increase in the cumulative WDR amount. Table 3 and Table 4 list the total measured WDR amount by each WDR gauge, as well as the corresponding error estimates for the rain event. The total error, $E_{T O T}$, consists of evaporation of adhered water droplets, $E_{A W}$, and the rest-water error, $E_{R W}$. The errors in WDR

measurements are estimated by assuming the total evaporation of the adhered amount of rain and of the amount that stays in tipping buckets during each dry period, which refer to the 10-min time intervals when the WDR registration is interrupted. The number of interruptions in the WDR registration is obtained by the number of plateaus in the experimental cumulative WDR graph in Fig. 9(c) and Fig. 10(c) rather than the horizontal rainfall intensity data in Fig. 8(a). This way, firstly, the interruptions due to possible delays in the rainfall registration by the tipping bucket of the horizontal rain gauge are not counted as dry periods. In fact, during some of these delays in horizontal rainfall registration, WDR registration still takes place due to the higher resolution of WDR tipping buckets. Secondly, taking the data from the horizontal rain gauge can be misleading for rain events, during which the wind direction changes a lot. In such cases, wind can approach from a direction where there is no WDR registration taking place even though rainfall is being registered. For example, no WDR is registered by any of the WDR gauges at around 03:00 on February 21, 2014. These periods should also be counted as dry periods, as there is some amount of evaporation on the WDR collectors. Consequently, the estimated error for the rain event on February 20-21, 2014 corresponds to 3 dry periods. For the rain event on February 20-21, 2014, it is found that the numerical model successfully estimates the WDR intensity in terms of cumulative WDR amounts during the rain event and catch ratio values at the end of the rain event.

\subsection{Rain event on August 2-3, 2014}

The meteorological data for the rain event on August 2-3, 2014 are shown in Fig. 8(b). The total rainfall amount at the end of the rain event is $18 \mathrm{~mm}$. The mean air temperature is $17.8^{\circ} \mathrm{C}$. This rain event is mainly composed of two separate and relatively short rain showers with higher rainfall intensity compared to the rain event on February 20-21, 2014. The wind direction fluctuates between west and east during the first rain shower, whereas the wind direction is less variable from west during the second rain shower. 
Fig. 11 compares the measured and numerical catch ratio values at the end of the rain event as well as the cumulative WDR amounts during the rain event on the west facade of building 1. For the total WDR sum at the end of the rain event, the deviations from the experimental values are $3.2 \%$ and $1.1 \%$ for the WDR gauges 1 and 2 , respectively. Fig. 12 compares the measured and numerical catch ratio values at the end of the rain event as well as the cumulative WDR amounts during the rain event on the west facade of building 2 . The contours of catch ratio show a similar wetting pattern to the one for the rain event on February 20-21, 2014. The gradient of catch ratio is slightly smaller for this rain event possibly due to higher rainfall intensity. For the total WDR sum at the end of the rain event, the numerical values on building 2 show average deviations of $7.1 \%$ from the experimental values at the upper half of the facade and of $5.2 \%$ at the bottom half. The average deviation along the central axis is only $2.7 \%$.

Fig. 11(c) and Fig. 12(c) show that during the first rain shower, the cumulative WDR is limited because the wind direction changes a lot during this period. The rainfall intensity and the wind speed values are similar during the second rain shower, but the cumulative WDR values are much higher due to wind direction being mostly from west. The difference between main wind directions during the two parts of the rain event can also be observed in the cumulative WDR graphs in Fig. 11(c) and Fig. 12(c). Table 5 and Table 6 list the total measured WDR amount by each WDR gauge, as well as the corresponding error estimates for the rain event. $E_{A W}$ and $E_{R W}$ estimations correspond to the 2 dry periods during which the WDR registration is interrupted. The number of dry periods is estimated in a similar way to the one in section 4.1. For the rain event on August 2-3, 2014, the numerical model successfully estimates the WDR intensity in terms of cumulative WDR amounts during the rain event and catch ratio values at the end of the rain event.

\section{Discussion}

\subsection{Turbulent dispersion of raindrops}

The influence of turbulent dispersion on the catch ratio can be quantified by solving the rain phase equations also once without the Reynolds stress term (third term on the left hand side in Eq. (3)). In the present study, the influence of turbulent dispersion is found to be up to $4 \%$ for building 1 . For building 2 , its influence is up to $3 \%$ at the top and up to $9 \%$ at the lower parts of the building. This is higher than the case with low-rise cubic buildings in Kubilay et al. [61], where the turbulent dispersion was found to be 3\% at most, both for upstream and downstream cubes. This difference between the 
influences of turbulent dispersion on catch ratio values in different geometries is mainly related to the larger size of building 2. As the building size increases, the neglect of turbulent dispersion of raindrops is no longer a valid assumption. The influence of turbulent dispersion of raindrops on the catch ratio values can be as high as $65 \%$ during rain events with low rainfall intensities at lower parts of a high-rise building [32].

\subsection{Flow patterns of wind and rain in the measurement geometry}

The validated numerical model can now be used to study the flow patterns of wind and rain and resulting catch ratio patterns in more detail. For both rain events, as presented in section 4, the catch ratio values on building 2 are lower compared to building 1 for position at the same height from the ground. The reason for this can be found by analyzing the flow patterns of wind and rain. Contours of the normalized mean wind speed and the streamlines of mean wind velocity in the vertical centerplane for the wind from west are shown in Fig. 13(a) and (b), respectively. Two thin separation zones on top of both buildings are shown in Fig. 13(a). The reattachment points of both are located on rooftops, at about 1/3H downstream, where $\mathrm{H}=2 \mathrm{~m}$ is the roof length. The acceleration of the wind flow over the roofs of both buildings is visible. The recirculation region between the two buildings extends more in the vertical direction compared to the standing vortex upstream of building 1 due to the higher position of the stagnation point at the windward facade of building 2. Moreover, Fig. 13(a) shows that the wind velocity in the recirculation region between the buildings is higher than the recirculation region upstream of building 1 . This is mainly because of the fact that the higher building 2 located downstream is diverting a larger amount of air downwards.

Fig. 13(c) compares the rain phase streamlines for raindrop sizes $d=0.3$ and $1.0 \mathrm{~mm}$ in the centerplane for wind from west at reference wind speed $U=3 \mathrm{~m} / \mathrm{s}$ at $y=2.4 \mathrm{~m}$ height. The streamlines for the droplet size of $0.3 \mathrm{~mm}$ are clearly strongly influenced by the recirculation regions in front of the low building, between both buildings and behind the high building. Note that some of the $0.3 \mathrm{~mm}$ droplets are impinging on the leeward facade of the taller downstream building. Such instances are observed for the smallest range of droplet sizes depending on the size of the recirculation region, wind speed and droplet size. However, for rainfall intensities larger than $1 \mathrm{~mm} / \mathrm{h}$, the probability of such small droplets is small. Therefore, the WDR intensity on the leeward facade is small and difficult to measure. The influences of the recirculation regions are much less pronounced for the raindrop size of $1.0 \mathrm{~mm}$ due to their larger inertia. The streamlines of $1.0 \mathrm{~mm}$ droplets are mostly parallel to each other upstream of the buildings. However, within the recirculation region between buildings 1 and 2,1.0 mm droplets also move away from the facade due to the influence of the recirculation region. This is 
due to the higher position of the vortex center between buildings 1 and 2 and the higher wind speed values within the recirculation region between buildings 1 and 2 . This behavior of larger droplets is the reason for lower catch ratio values at the middle height of building 2 compared to the top part of the upstream building 1, even though these regions are at the same height from ground. Such a behavior is not observed in the recirculation regions upstream of building 1, where the weaker recirculation region has little influence on the streamlines of the $1.0 \mathrm{~mm}$ droplets. The resulting catch ratio distribution is shown in Fig. 13(d) for wind from west at a reference wind speed of $U=3 \mathrm{~m} / \mathrm{s}$ and reference rainfall intensity $R_{h}=1 \mathrm{~mm} / \mathrm{h}$.

\subsection{Influence of building configurations on the resulting WDR intensity}

Combined influences of various wind-flow patterns in other building configurations and the resulting catch ratio distributions are studied using the validated numerical model. Fig. 14 presents the catch ratio distributions for a reference wind speed of $3 \mathrm{~m} / \mathrm{s}$ at $y=2.4 \mathrm{~m}$ height and a reference rainfall intensity of $1 \mathrm{~mm} / \mathrm{h}$ for 3 different building configurations. Furthermore, the contours of the normalized mean wind speed in the vertical centerplane are shown. Case 1 in Fig. 14(a) is composed of an isolated building which is identical to the building 2 in the base case, i.e. the measurement geometry. The standing vortex is visible upstream of the building. However, the wind speed within the standing vortex is lower than the recirculation region between the two buildings in the base case as shown in Fig. 13(a). Besides, the accelerated wind flow over the roof of building 1 in Fig. 13(a) is also missing. Case 2 in Fig. 14(b) is composed of two parallel buildings with a configuration similar to the base case except for the width of the buildings, which is $20 \mathrm{~m}$ instead of $6 \mathrm{~m}$. The wind-flow patterns observed for this case are similar to the ones in the base case in Fig. 13(a), i.e. the sizes and locations of recirculation regions. However, the wind speed values observed between the two buildings are much lower in this case, mainly due to the larger sizes of both buildings, i.e. larger wind-blocking effect [18]. Fig. 14(c) presents the results for case

3 , which is composed of two parallel buildings with the same heights. The sizes of the buildings are identical to the building 2 in the base case and the distance between the two buildings is $2 \mathrm{~m}$, i.e. the same as the distance between buildings 1 and 2 in the base case. The catch ratio pattern on the upstream building is very similar to the one observed on the isolated building in case 1 (Fig. 14(a)). The downstream building shows a catch ratio pattern with a larger gradient showing much smaller values at the lower part of its facade. The wind speed values between the two buildings are quite low compared to the base case in Fig. 13(a). 
Different wind-flow profiles in different building configurations have conflicting effects on the catch ratio distribution on the downstream building. These effects are identified to be due to sheltering, wind-blocking effect, recirculation regions and acceleration of wind over the roof of the upstream building. Fig. 15 compares the specific catch ratio values observed along a vertical line in the middle of the facades of the downstream building in each case for raindrop sizes $d=1.0$ and $5.0 \mathrm{~mm}$ for wind from west at a reference wind speed of $3 \mathrm{~m} / \mathrm{s}$. The positions of the lines are indicated in Fig. 15. At the top of the facades, all configurations lead to similar values of catch ratio for each droplet size. For the droplet size of $1.0 \mathrm{~mm}$, the base case has larger catch ratio values along a large part of the line compared to case 1 . This is mainly due to the accelerated flow over the roof of building 1 and the larger recirculation region between buildings 1 and 2 showing higher wind speeds. The presence of the lower building located upstream increases the catch ratio values on the downstream building instead of sheltering. As the width of the buildings are increased, the wind-blocking effect increases and the approach-flow wind speed becomes lower. It is shown in Fig. 14(b) that, in case 2, the wind-blocking effect leads to a recirculation region with lower wind speeds between the buildings. Therefore, the catch ratio values are lower than the one observed in case 1 at the lower half of the facade. The lowest catch ratio values are observed for case 3, where a large amount of WDR is sheltered by the upstream building, which leads to much smaller catch ratio at the lower $3 / 4^{\text {th }}$ of the facade compared to all other cases. For the droplet size of $5.0 \mathrm{~mm}$, the gradients of catch ratio along the lines are smaller for all cases. The relation between the catch ratio values for the base case and cases 1 and 2 are similar to the droplet size of $1.0 \mathrm{~mm}$. However, the influences of wind-flow patterns and, hence, the difference between the catch ratios are much smaller. On the other hand, the sheltering effect observed for case 3 is still present at the lower half of the building.

\subsection{Limitations}

In the present study, the numerical catch ratios are mean values based on steady RANS calculations. However, the instantaneous values during a rain event may show higher or lower catch ratio values than the ones reported in this paper. In order to obtain the instantaneous catch ratio values, i.e. the peaks of the highest catch ratio values and their locations, unsteady calculations of WDR can be an option using unsteady RANS (URANS), large eddy simulation (LES) or detached eddy simulation (DES). In the present study, the temporal changes in the meteorological conditions during a rain event are taken into account by considering the 10-min experimental timesteps as steady-state [10]. By performing WDR simulations coupled with LES wind-flow calculations, Kubilay [62] shows that the mean specific catch ratios, with an averaging time of about 100-200 s, indeed agree well with the specific catch ratio values estimated with RANS calculations. On the other 
hand, it is observed that the instantaneous specific catch ratio values of smaller droplets fluctuate a lot around the mean value, i.e. the root mean square of specific catch ratio of smaller droplets is larger than the one of larger droplets.

\section{Conclusion}

This paper presents a new measurement setup for wind-driven rain (WDR), composed of two parallel wide buildings with different heights. The measurement setup is designed and installed at the Swiss Federal Laboratories for Materials Science and Technology (Empa) in Dübendorf, Switzerland. The paper provides the description of the measurement geometry, surroundings of the measurement area, measuring equipment, as well as the experimental data of three selected rain events.

The complete dataset of rain events can be downloaded from the given website. The dataset provides insight into the way buildings mutually influence WDR distributions by interacting with their exposures to wind and rain. It is intended as a tool for model development, verification and validation. The numerical model using an Eulerian multiphase (EM) model including turbulent dispersion of raindrops is validated by comparing cumulative WDR amounts during two rain events as well as the catch ratio values at the end of these rain events with the corresponding experimental data. It is found that the numerical model successfully estimates the WDR intensity on both buildings. The average discrepancy between the numerical and experimental results is found to be $6.9 \%$ for the rain event on February 20-21, 2014 and $4.9 \%$ for the rain event on August 2-3, 2014. Furthermore, the influence of geometry on wind-flow patterns and catch ratio distributions is studied in various configurations of parallel buildings. The configuration and size of building groups influence the WDR intensity through factors such as recirculation regions, sheltering, wind-blocking effect and acceleration of wind over the roof. These factors are found to have conflicting effects on the catch ratio distribution of the downstream building. Recirculation regions and acceleration of wind over the roof of the upstream building increase the catch ratio on the windward facade of the downstream building, whereas wind-blocking effect and sheltering decrease the catch ratio.

\section{Acknowledgments}

The research was supported through the Swiss National Science Foundation (SNF) - Project no. 135510. 


\section{References}

[1] Van Balen K. Expert system for evaluation of deterioration of ancient brick masonry structures. Sci Total Environ. 1996;189:247-254.

[2] Franke L, Schumann I, van Hees R, van der Klugt L, Naldini S, Binda L, Baronio G, van Balen K, Mateus J. Damage atlas: classification and analyses of damage patterns found in brick masonry. European Commision Research report No 8, vol 2, Fraunhofer IRB Verlag. 1998.

[3] Tang W, Davidson CI, Finger S, Vance K. Erosion of limestone building surfaces caused by wind-driven rain: 1. Field measurements. Atmos Environ. 2004;38:5589-5599.

[4] Erkal A, D'Ayala D, Sequeira L. Assessment of wind-driven rain impact, related surface erosion and surface strength reduction of historic building materials. Build Environ. 2012;57:336-348.

[5] Charola AE, Lazzarini L. Deterioration of brick masonry caused by acid rain. ACS Symp Series 318. 1986:250-258.

[6] Davidson CI, Tang W, Finger S, Etyemezian V, Striegel M, Sherwood SI. Soiling patterns on a tall limestone building: changes over 60 years. Environ Sci Technol. 2000;34:560-565.

[7] Etyemezian V, Davidson CI, Zufall M, Dai W, Finger S, Striegel M. Impingement of rain drops on a tall building. Atmos Environ. 2000;34:2399-2412.

[8] Abuku M, Janssen H, Roels S. Impact of wind-driven rain on historic brick wall buildings in a moderately cold and humid climate: Numerical analyses of mould growth risk, indoor climate and energy consumption. Energ Buildings. 2009;41:101-110.

[9] Blocken B, Dezso G, van Beeck J, Carmeliet J. The mutual influence of two buildings on their wind-driven rain exposure and comments on the obstruction factor. J Wind Eng Ind Aerod. 2009;97:180-196.

[10] Blocken B, Carmeliet J. Spatial and temporal distribution of driving rain on a low-rise building. Wind Struct. 2002;5:441-462.

[11] Blocken B, Carmeliet J. A review of wind-driven rain research in building science. J Wind Eng Ind Aerod. 2004;92:1079-1130.

[12] Blocken B, Carmeliet J. Overview of three state-of-the-art wind-driven rain assessment models and comparison based on model theory. Build Environ. 2010;45:691-703.

[13] Blocken B, Derome D, Carmeliet J. Rainwater runoff from building facades: A review. Build Environ. 2013;60:339-361.

[14] Blocken B. 50 years of Computational Wind Engineering: Past, present and future. J Wind Eng Ind Aerod. 2014;129:69-102.

[15] Blocken B, Carmeliet J. High-resolution wind-driven rain measurements on a low-rise building - experimental data for model development and model validation. J Wind Eng Ind Aerod. 2005;93:905-928.

[16] Kubilay A, Derome D, Blocken B, Carmeliet J. High-resolution field measurements of wind-driven rain on an array of low-rise cubic buildings. Build Environ. 2014;78:1-13.

[17] van Mook FJR. Driving rain on building envelopes. Ph.D. thesis, Eindhoven University of Technology, Eindhoven, The Netherlands; 2002.

[18] Blocken B, Carmeliet J. The influence of the wind-blocking effect by a building on its wind-driven rain exposure. J Wind Eng Ind Aerod. 2006;94:101-127.

[19] Blocken B, Carmeliet J. Validation of CFD simulations of'wind-driven rain on a low-rise building facade. Build Environ. 2007;42:2530-2548.

[20] Briggen PM, Blocken B, Schellen HL. Wind-driven rain on the facade of a monumental tower: numerical simulation, full-scale validation and sensitivity analysis. Build Environ. 2009;44:1675-1690.

[21] Choi ECC. Numerical simulation of wind-driven rain falling onto a 2-D building. Asia Pacific Conf. on Computational Mechanics, Hong Kong. 1991. p. 1721-1728.

[22] Choi ECC. Simulation of wind-driven-rain around a building. J Wind Eng Ind Aerod. 1993;46-47:721-729.

[23] Choi ECC. Determination of wind-driven-rain intensity on building faces. J Wind Eng Ind Aerod. 1994;51:55-69.

[24] Choi ECC. Modelling of wind-driven rain and its soil detachment effect on hill slopes. J Wind Eng Ind Aerod. 2002;90:1081-1097.

[25] Hangan H. Wind-driven rain studies. A C-FD-E approach. J Wind Eng Ind Aerod. 1999;81:323-331.

[26] Tang W, Davidson CI. Erosion of limestone building surfaces caused by wind-driven rain: 2. numerical modeling. Atmos Environ. 2004;38:5601-5609.

[27] Abuku M, Blocken B, Nore K, Thue JV, Carmeliet J, Roels S. On the validity of numerical wind-driven rain simulation on a rectangular low-rise building under various oblique winds. Build Environ. 2009;44:621-632.

[28] van Hooff T, Blocken B, van Harten M. 3D CFD simulations of wind flow and wind-driven rain shelter in sports stadia: Influence of stadium geometry. Build Environ. 2011;46:22-37.

[29] Mohaddes Foroushani SS, Ge H, Naylor D. Effects of roof overhangs on wind-driven rain wetting of a low-rise cubic building: A numerical study. J Wind Eng Ind Aerod. 2014;125:38-51.

[30] Huang SH, Li QS. Numerical simulations of wind-driven rain on building envelopes based on Eulerian multiphase model. J Wind Eng Ind Aerod. 2010;98:843-857.

[31] Kubilay A, Derome D, Blocken B, Carmeliet J. CFD simulation and validation of wind-driven rain on a building facade with an Eulerian multiphase model. Build Environ. 2013;61:69-81.

[32] Kubilay A, Derome D, Blocken B, Carmeliet J. Numerical modeling of turbulent dispersion for wind-driven rain on building facades. Environ Fluid Mech. 2015;15:109-133.

[33] Lacy RE. Driving-rain maps and the onslaught of rain on buildings. RILEM/CIB Symposium on Moisture Problems in Buildings, Helsinki, Finland. 1965.

[34] Brown B. Field measurements to gauge catch ratios of free-space driving rain on house walls at exposed estates in Dorset. Building Research Establishment Note. 1988. 
[35] Nore K, Blocken B, Jelle BP, Thue JV, Carmeliet J. A dataset of wind-driven rain measurements on a low-rise test building in Norway. Build Environ. 2007;42:2150-2165.

[36] Ge H, Krpan R, Fazio P. Field measurements of wind-driven rain: A study of seven buildings in Metro Vancouver. Proceedings of the 12th Canadian Conference on Building Science and Technology, May, Montreal, Quebec. 2009.

[37] Blocken B, Carmeliet J. On the accuracy of wind-driven rain measurements on buildings. Build Environ. 2006;41:1798-1810.

[38] Dunkerley D. Identifying individual rain events from pluviograph records: a review with analysis of data from an Australian dryland site. Hydrol Process. 2008;22:5024-5036.

[39] van der Hoven I. Power spectrum of horizontal wind speed in the frequency range from 0.0007-900 cycles per hour. J Meteo. 1957; 14:160-164.

[40] Sumner GN. The nature and development of rainstorms in Coastal East Africa. J Climatol. 1981;1:131-152.

[41] Blocken B, Carmeliet J. On the errors associated with the use of hourly data in wind-driven rain calculations on building facades. Atmos Environ. 2007;41:2335-2343.

[42] Blocken B, Carmeliet J. Guidelines for the required time resolution of meteorological input data for wind-driven rain calculations on buildings. J Wind Eng Ind Aerod. 2008;96:621-639.

[43] Yakhot V, Orszag SA, Thangam S, Gatski TB, Speziale CG. Development of turbulence models for shear flows by a double expansion technique. Phys Fluids A-Fluid. 1992;4:1510-1520.

[44] Best AC. The size distribution of raindrops. Q J Roy Meteor Soc. 1950;76:16-36.

[45] Gunn R, Kinzer GD. The terminal velocity of fall for water droplets in stagnant air. J Meteorol. 1949;6:243-248.

[46] Richards PJ, Hoxey RP. Appropriate boundary conditions for computational wind engineering models using the k- $€$ turbulence model. J Wind Eng Ind Aerod. 1993;46-47:145-153.

[47] Blocken B, Carmeliet J, Stathopoulos T. CFD evaluation of wind speed conditions in passages between parallel buildings - effect of wall-function roughness modifications for the atmospheric boundary layer flow. J Wind Eng Ind Aerod. 2007;95:941-962.

[48] Blocken B, Stathopoulos T, Carmeliet J. CFD simulation of the atmospheric boundary layer: wall function problems. Atmos Environ. 2007;41:238-252.

[49] Hargreaves DM, Wright NG. On the use of the k-epsilon model in commercial CFD software to model the neutral atmospheric boundary layer. J Wind Eng Ind Aerod. 2007;95:355-369.

[50] O'Sullivan JP, Archer RA, Flay RGJ. Consistent boundary conditions for flows within the atmospheric boundary layer. J Wind Eng Ind Aerod. 2011;99:65-77.

[51] Parente A, Gorle C, van Beeck J, Benocci C. Improved kappa-epsilon model and wall function formulation for the RANS simulation of ABL flows. J Wind Eng Ind Aerod. 2011;99:267-278.

[52] Tominaga Y, Mochida A, Yoshie R, Kataoka H, Nozu T, Yoshikawa M, Shirasawa T. AIJ guidelines for practical applications of CFD to pedestrian wind environment around buildings. J Wind Eng Ind Aerodyn. 2008;96:1749-1761.

[53] Franke J, Hellsten A, Schlunzen KH, Carissimo B. The COST 732 Best practice guideline for CFD simulation of flows in the urban environment: a summary. Int J Environ Pollut. 2011;44:419-427.

[54] Launder BE, Spalding DB. The numerical computation of turbulent flows. Comput Methods Appl Mech Eng. 1974:269-289.

[55] Cebeci T, Bradshaw P. Momentum transfer in boundary layers. New York: Hemisphere Publishing Corporation; 1977.

[56] Wieringa J. Updating the Davenport roughness classification. J Wind Eng Ind Aerod. 1992;41:357-368.

[57] de Wolf DA. On the Laws-Parsons distribution of raindrop sizes. Radio Sci. 2001;36:639-642.

[58] Pope SB. Turbulent flows: Cambridge University Press; 2000.

[59] Defraeye TWJ. Convective heat and mass transfer at exterior building surfaces. Ph.D. thesis, Katholieke Universiteit Leuven, Leuven, Belgium.; 2011.

[60] OpenCFD Ltd. OpenFOAM v2.2.2 User guide openfoam. 2013.

[61] Kubilay A, Derome D, Blocken B, Carmeliet J. Numerical simulations of wind-driven rain on an array of low-rise cubic buildings and validation by field measurements. Build Environ. 2014;81:283-295.

[62] Kubilay A. Numerical simulations and field experiments of wetting of building facades due to wind-driven rain in urban areas: Ph.D. thesis, ETH Zurich, Switzerland; 2014. 


\section{Figures}

a)

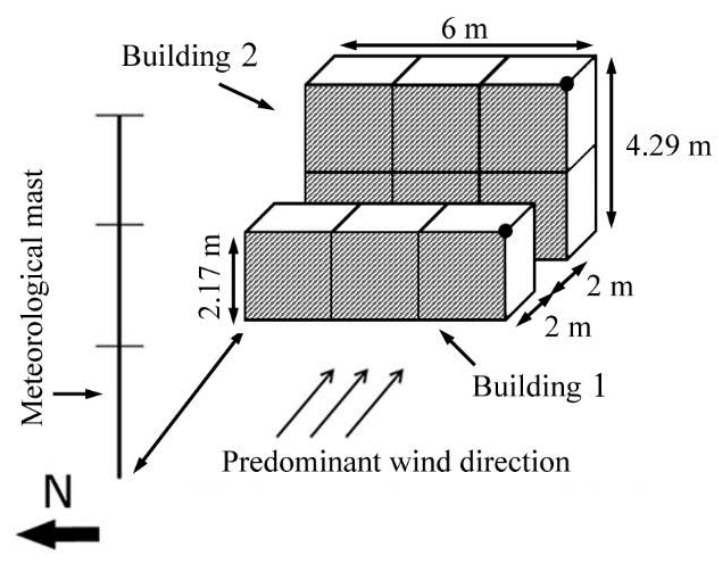

b)

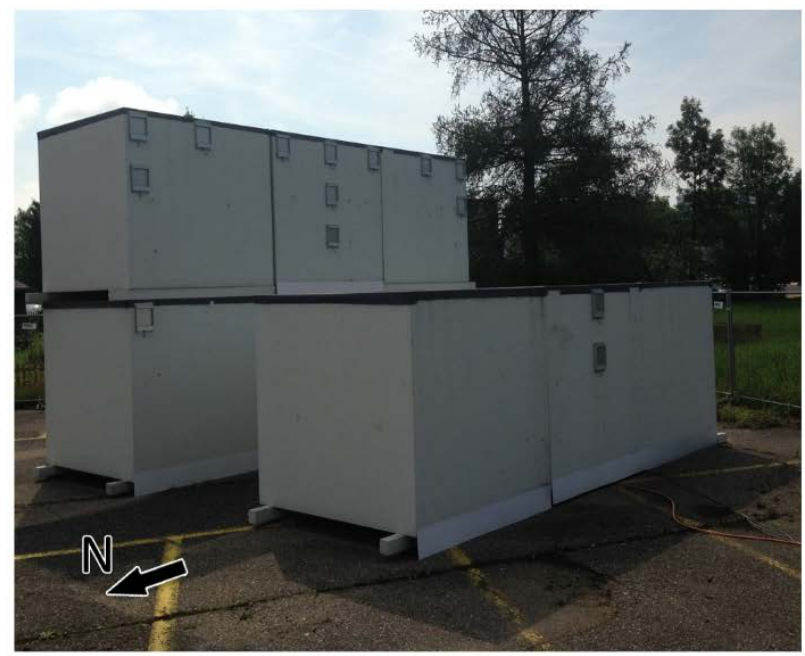

c)

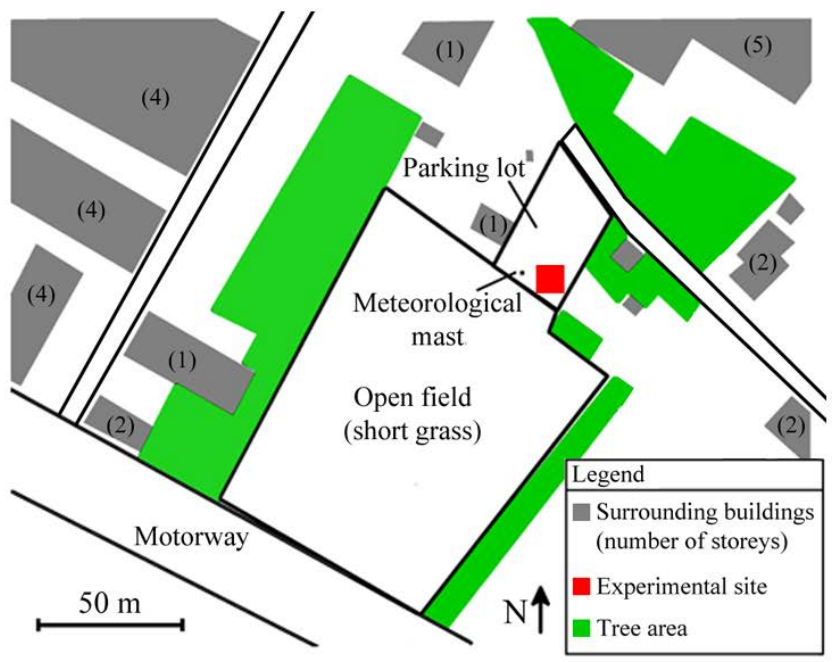

Fig. 1. a) Geometry of the two parallel buildings for field measurements. The WDR measurements are conducted on the grey facades. b) Photograph of the measurement site from northwest, taken on July 28, 2014. c) Plan of the experimental site and its surroundings. 


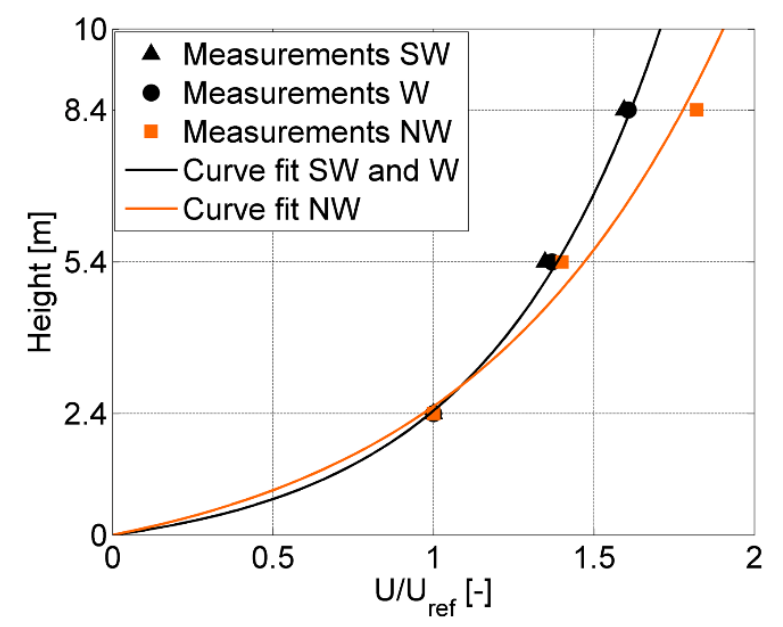

Fig. 2. Measurements and a log-law fit for the scaled approach-flow wind speed profiles for wind direction from southwest, west and northwest.

a)

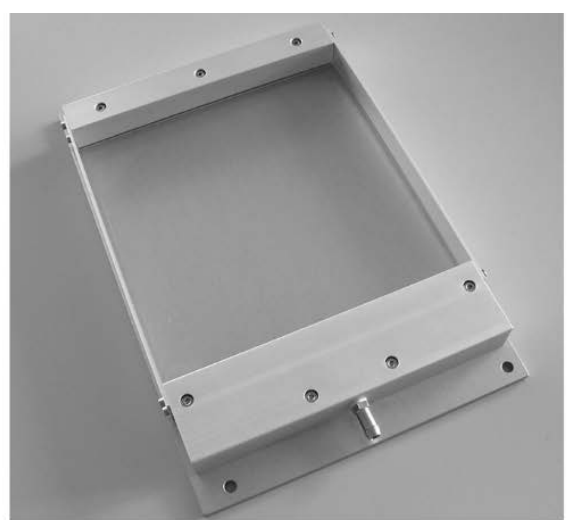

b)

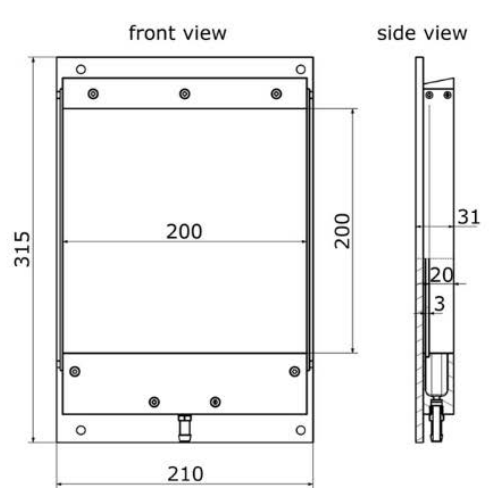

c)

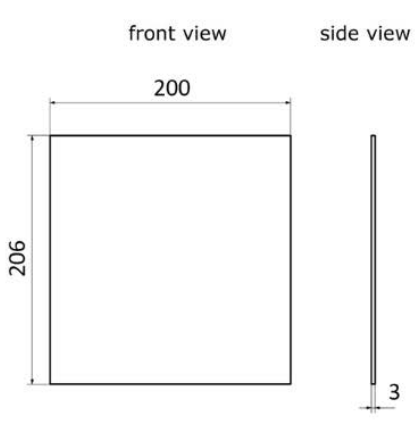

Fig. 3. a) View of the wind-driven rain gauge collector. b) Dimensions (in $\mathrm{mm}$ ) of the wind-driven rain gauge collector from the front and side. c) Dimensions (in $\mathrm{mm}$ ) of the glass surface. 
a)

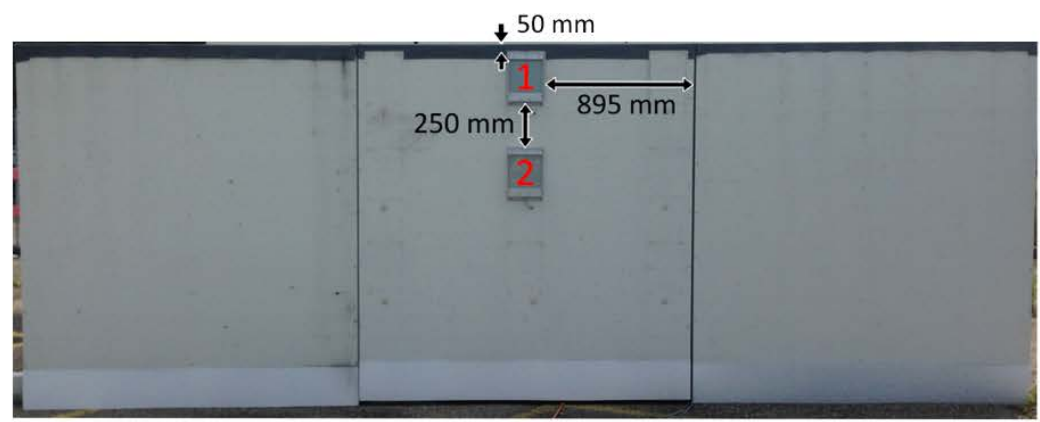

b)

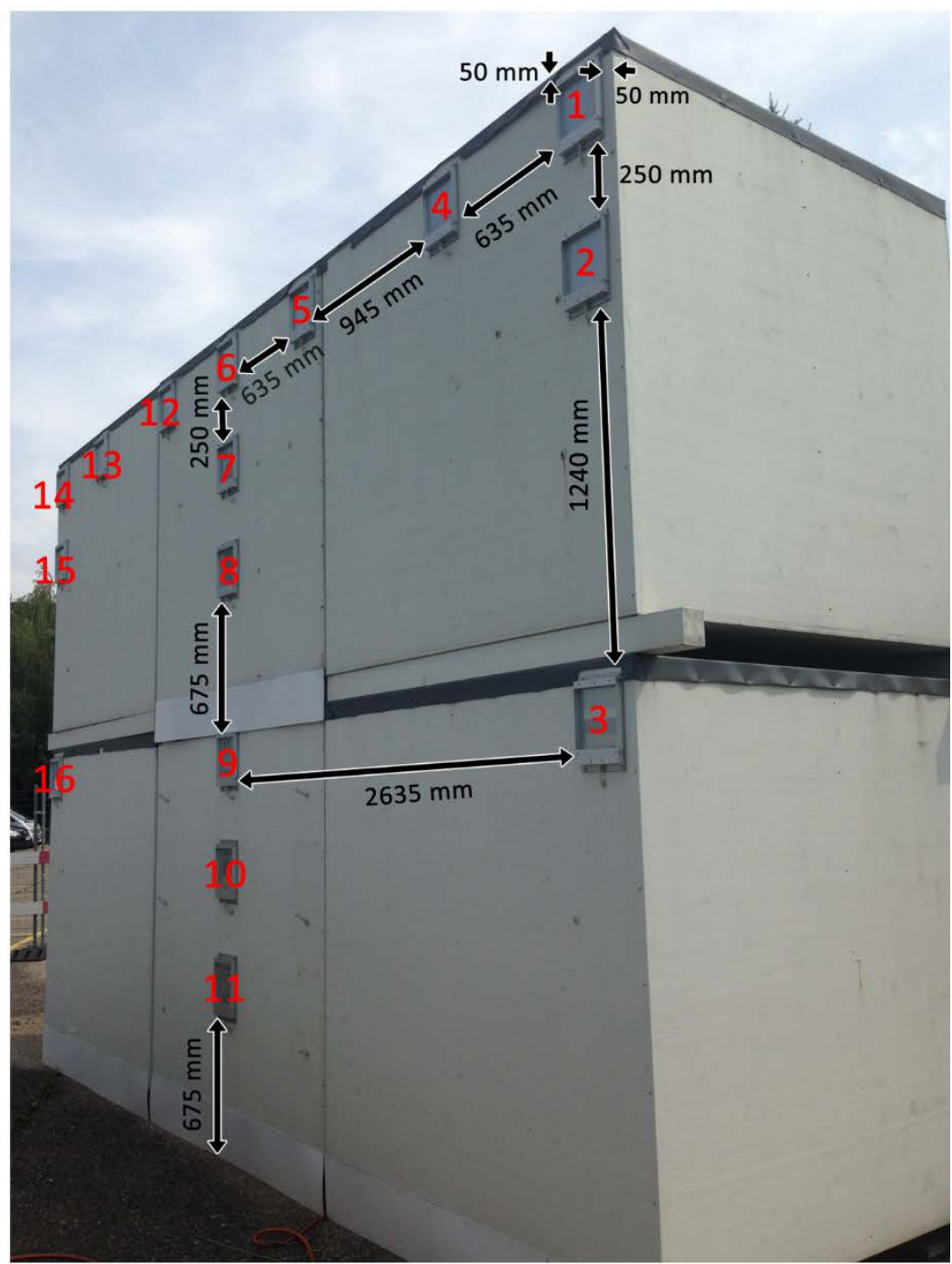

Fig. 4. Positions of wind-driven rain gauges on buildings a) 1 and b) 2 . 


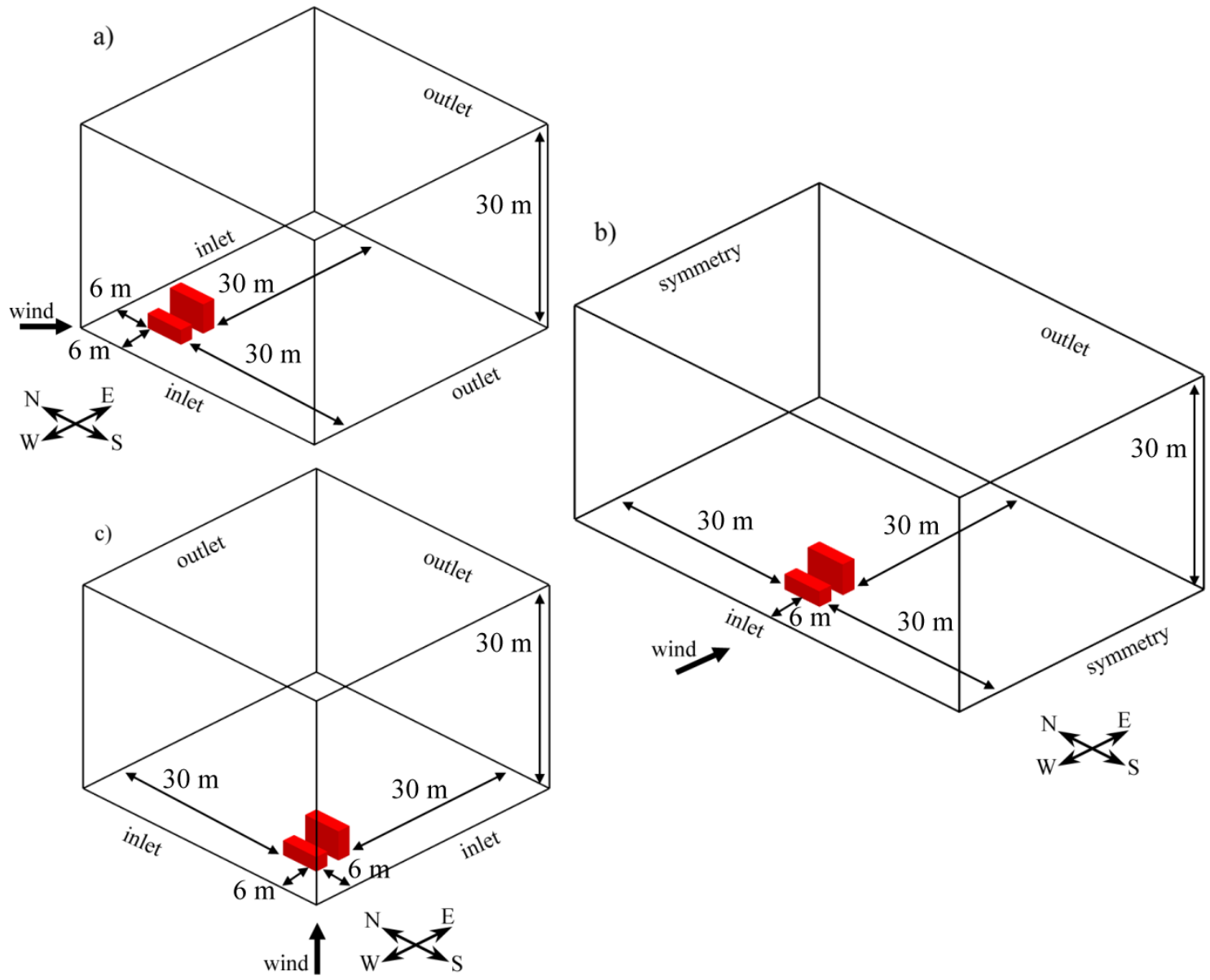

Fig. 5. The computational domains for wind from a) northwest, b) west and c) southwest. 


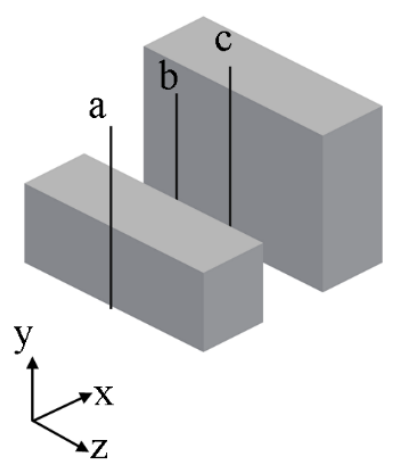

b)

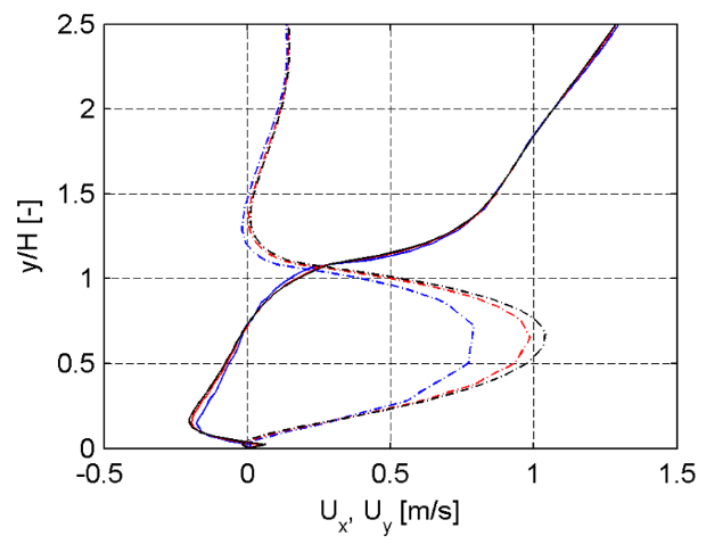

a)
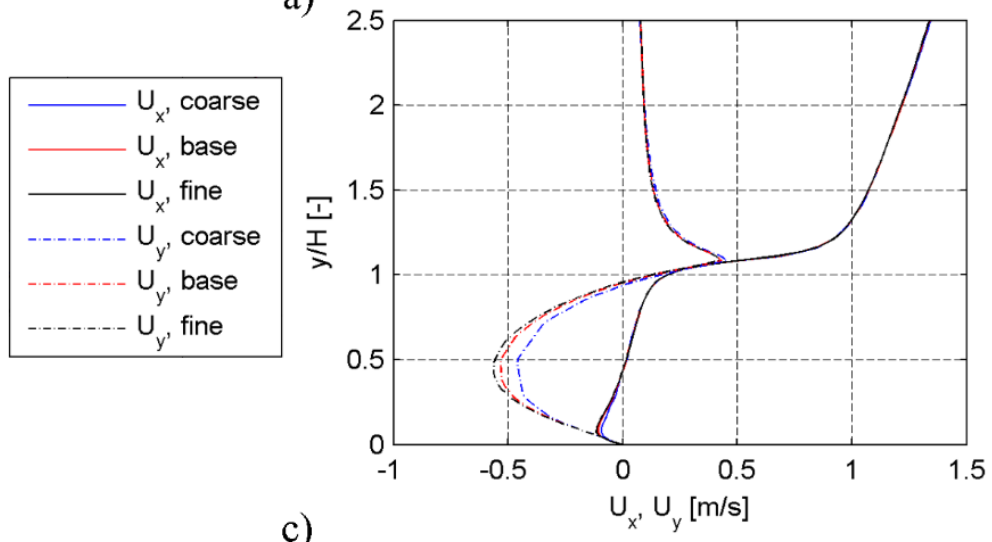

c)

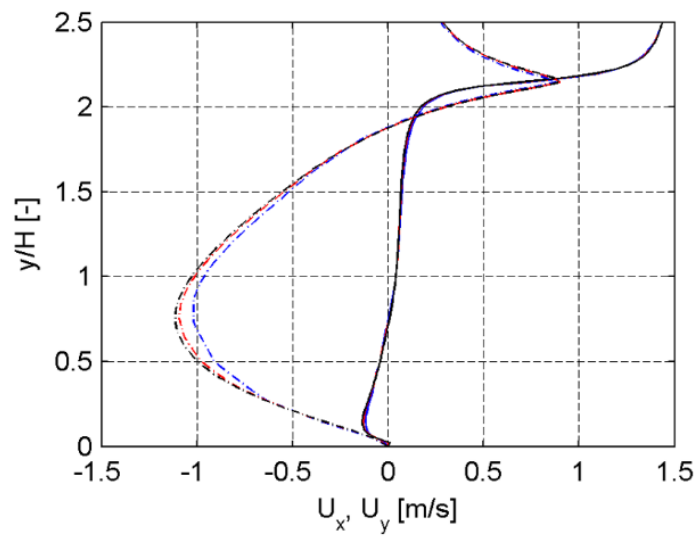

Fig. 6. Grid-sensitivity analysis comparing streamwise, $U_{x}$, and vertical, $U_{y}$, wind velocity components on three different grids (coarse, base, fine) along lines positioned a) upstream of, b) downstream of building 1 and c) upstream of building 2 all in the centerplane.

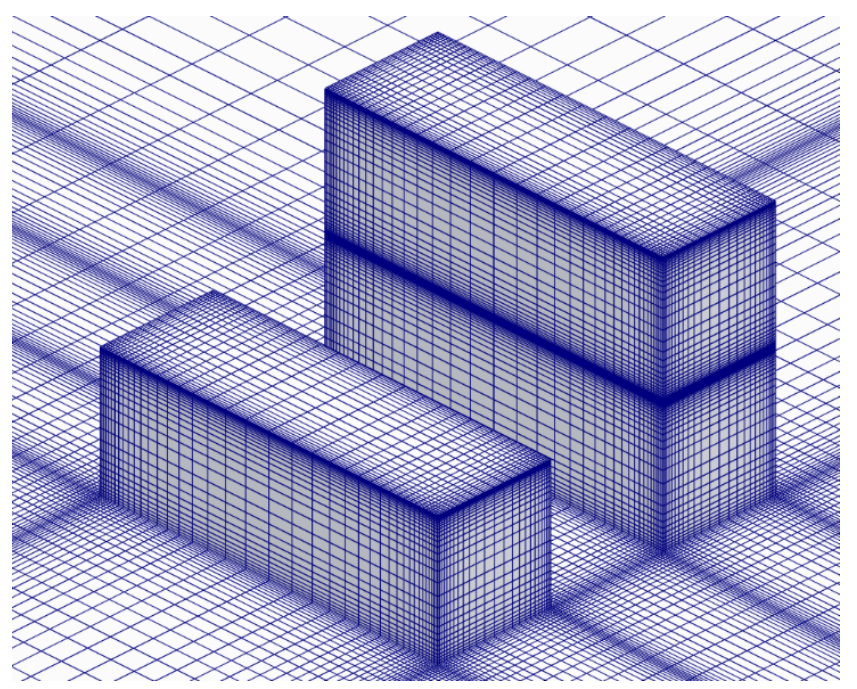

Fig. 7. Computational grid on the buildings and on part of the ground surface (1 318912 cells). 
a)

February $20-21,2014$
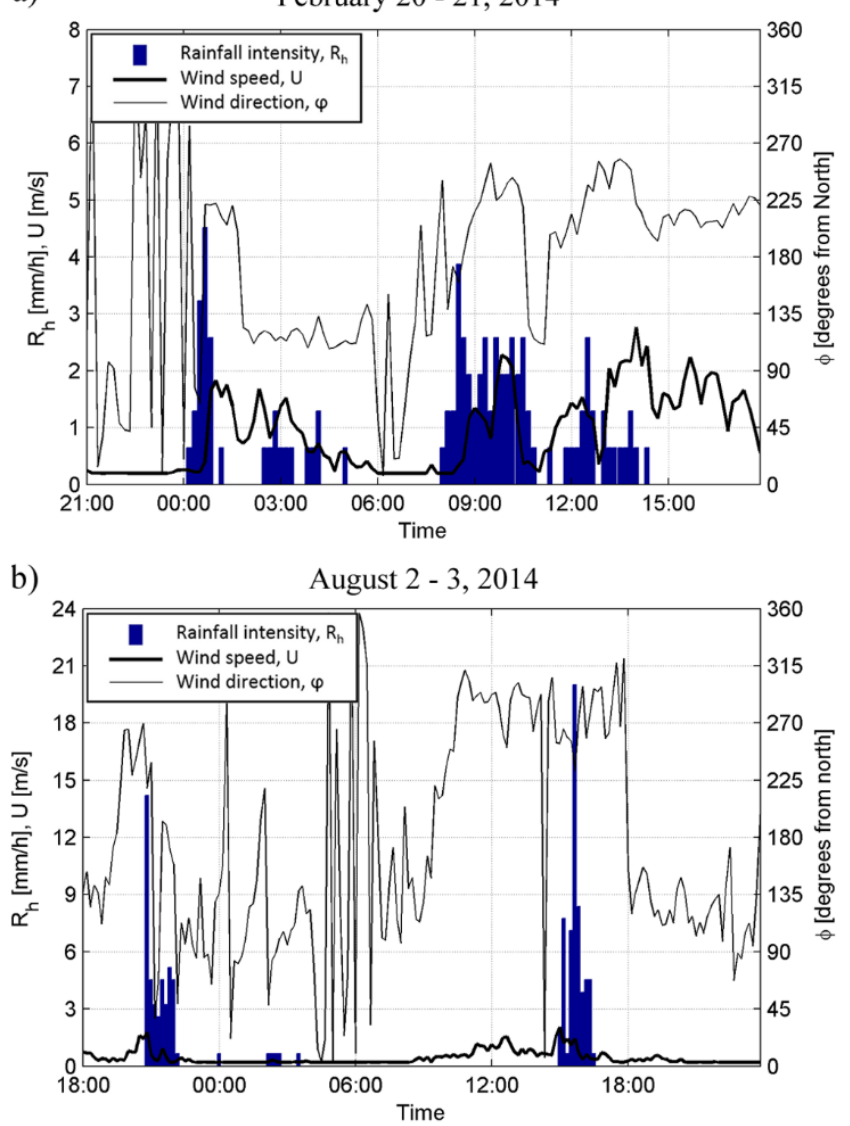

Fig. 8. a) Meteorological data for the rain event on a) February 20-21, 2014 and b) August 2-3, 2014 using 10-min experimental time steps. Reference wind speed is measured at $2.4 \mathrm{~m}$ height from the ground. 
a)

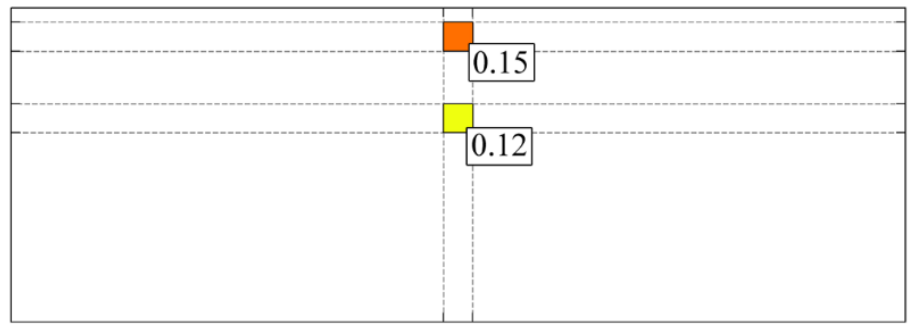

b)

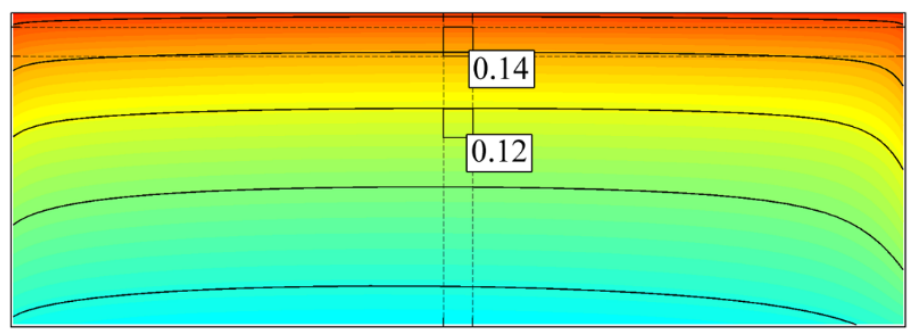

\section{$\eta[-]$}

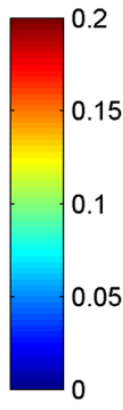

c)

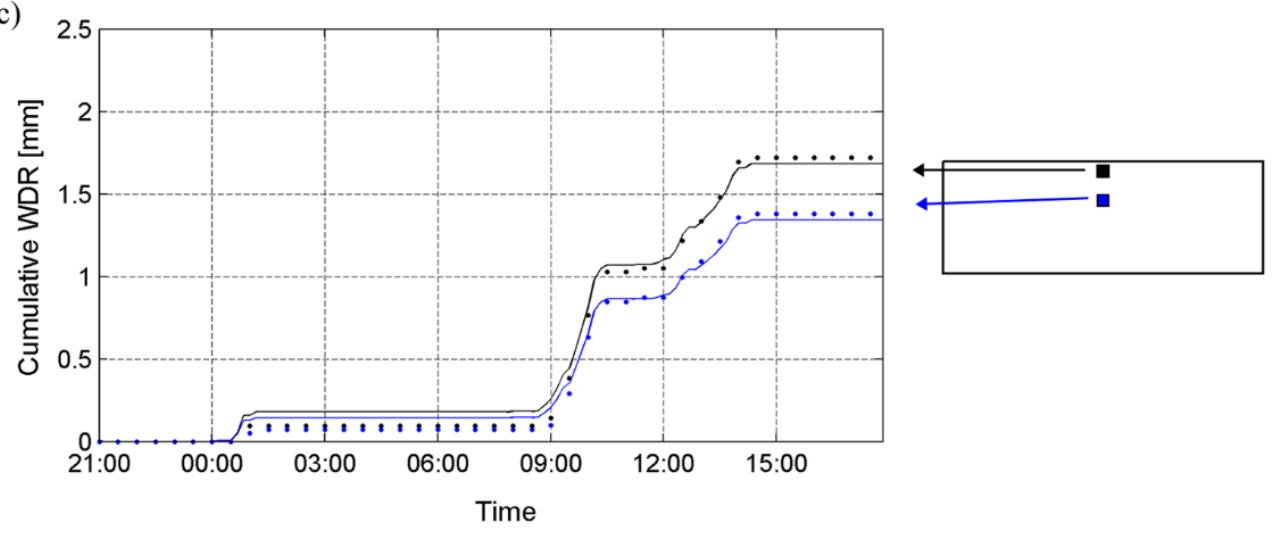

Fig. 9. Comparison of a) experimental and b) numerical catch ratio data on the west facade of building 1 after the rain event on February 20-21, 2014. c) Comparison of experimental (dots) and numerical (lines) cumulative WDR amounts on building 1 during the rain event on February 20-21, 2014. 
a)

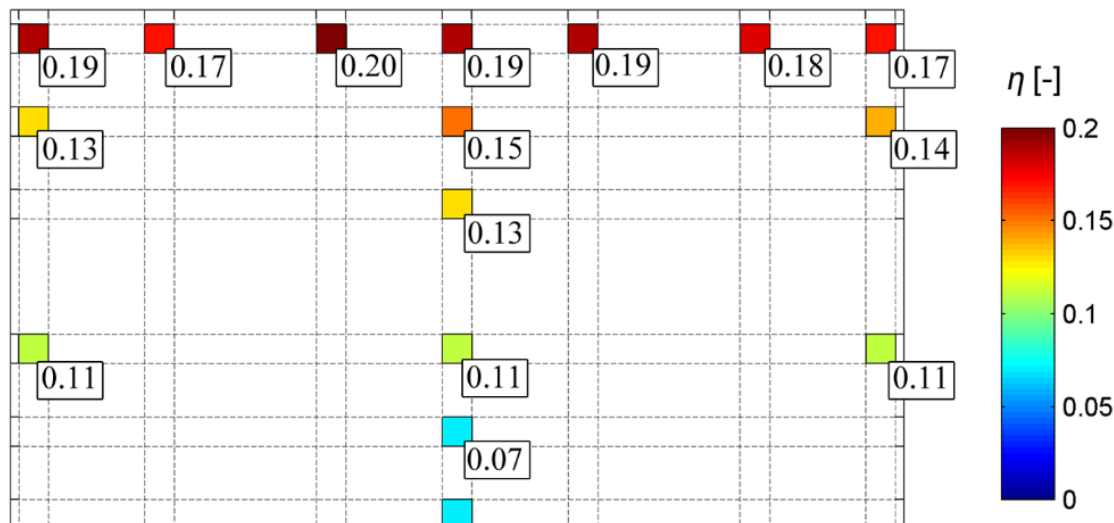

b)

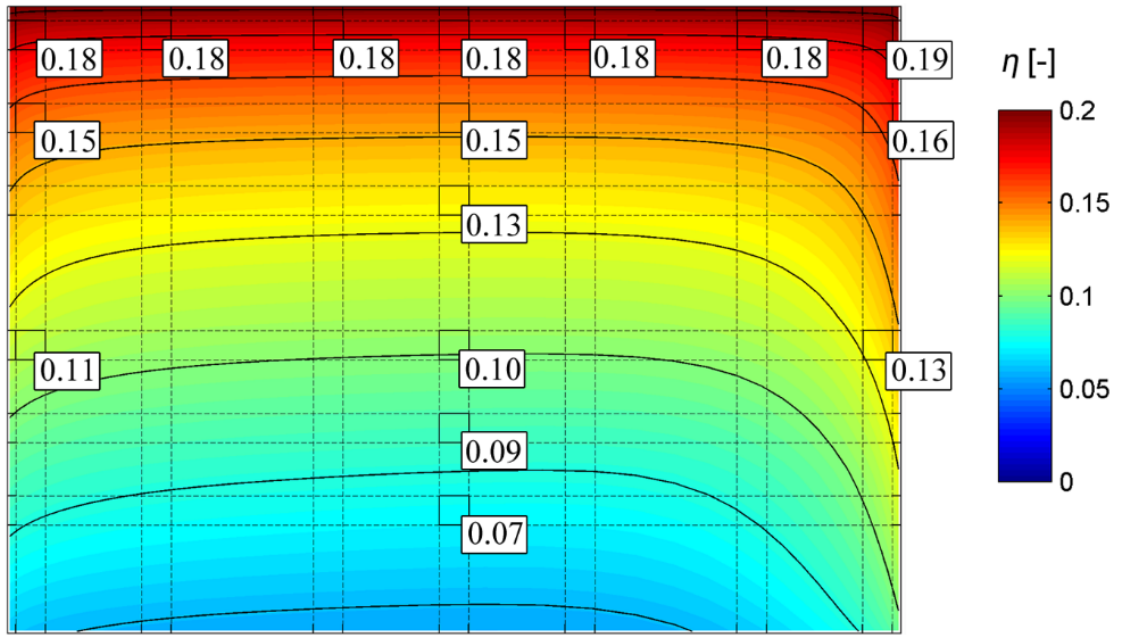

c)

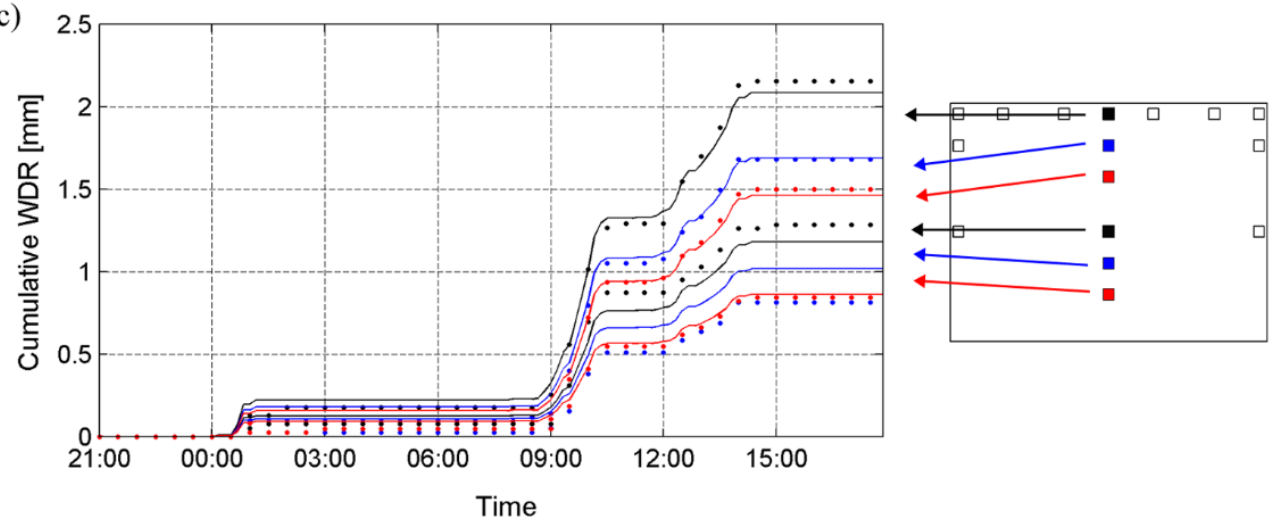

Fig. 10. Comparison of a) experimental and b) numerical catch ratio data on the west facade of building 2 after the rain event on February 20-21, 2014. c) Comparison of experimental (dots) and numerical (lines) cumulative WDR amounts on building 2 during the rain event on February 20-21, 2014. 
a)

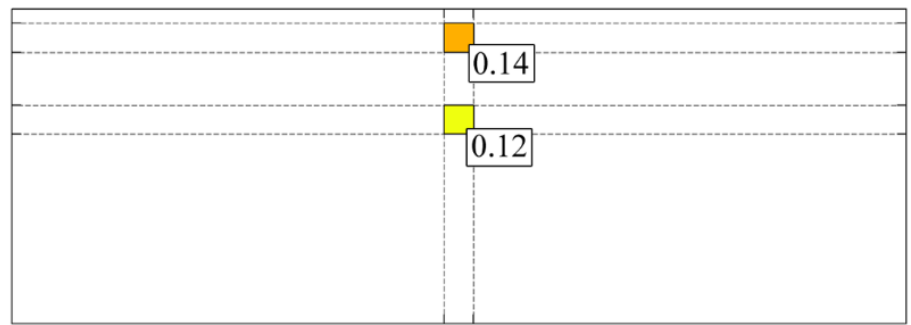

b)
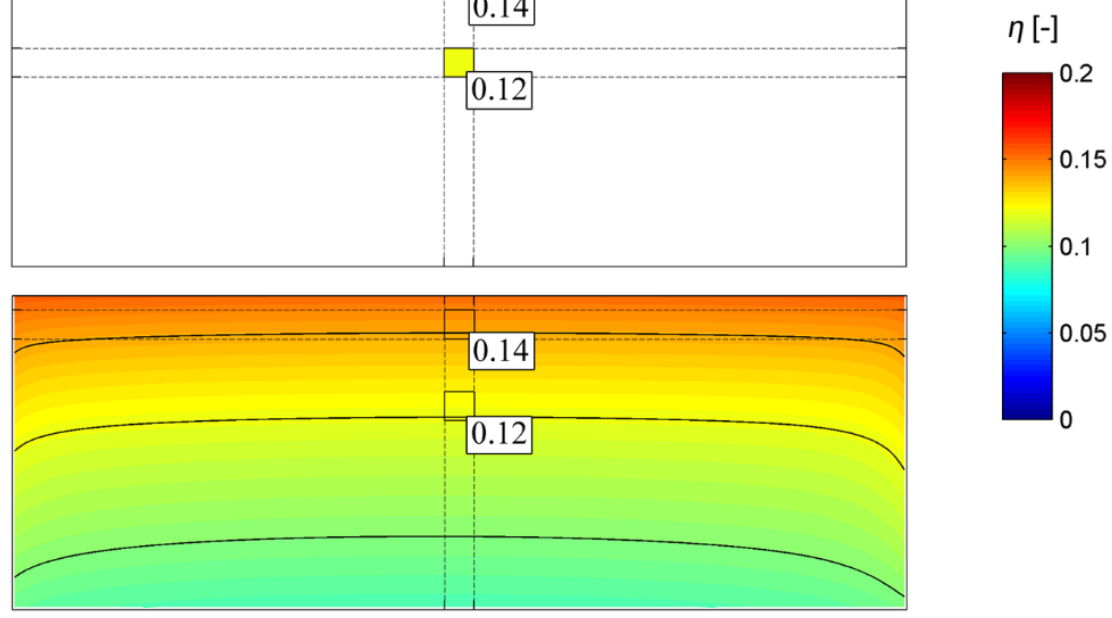

c)

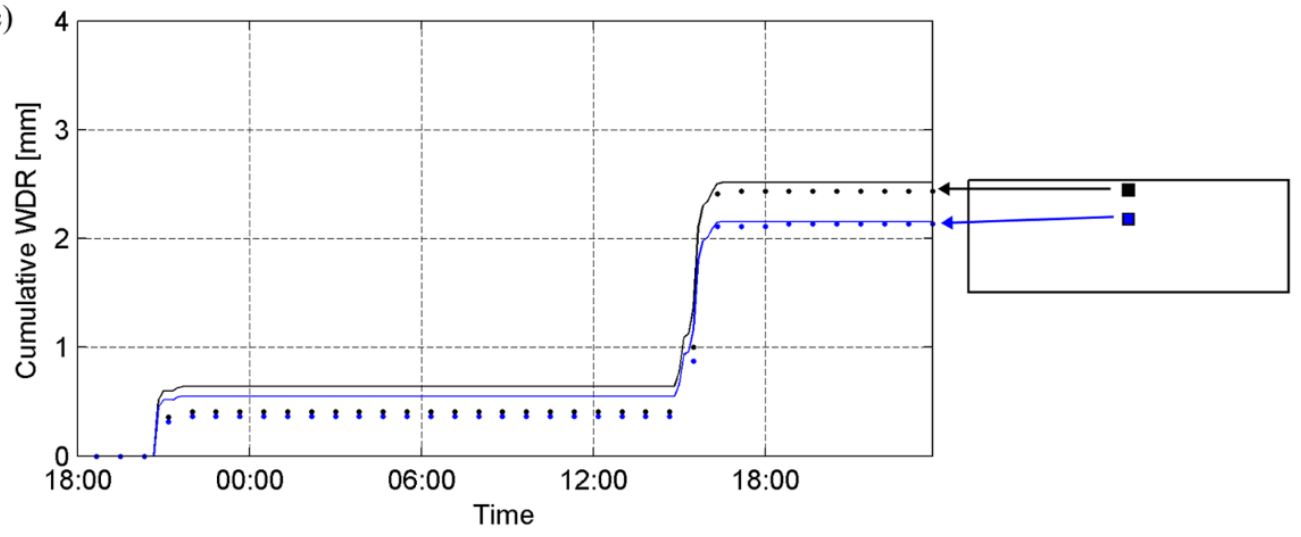

Fig. 11. Comparison of a) experimental and b) numerical catch ratio data on the west facade of building 1 after the rain event on August 2-3, 2014. c) Comparison of experimental (dots) and numerical (lines) cumulative WDR amounts on building 1 during the rain event on August 2-3, 2014. 
a)

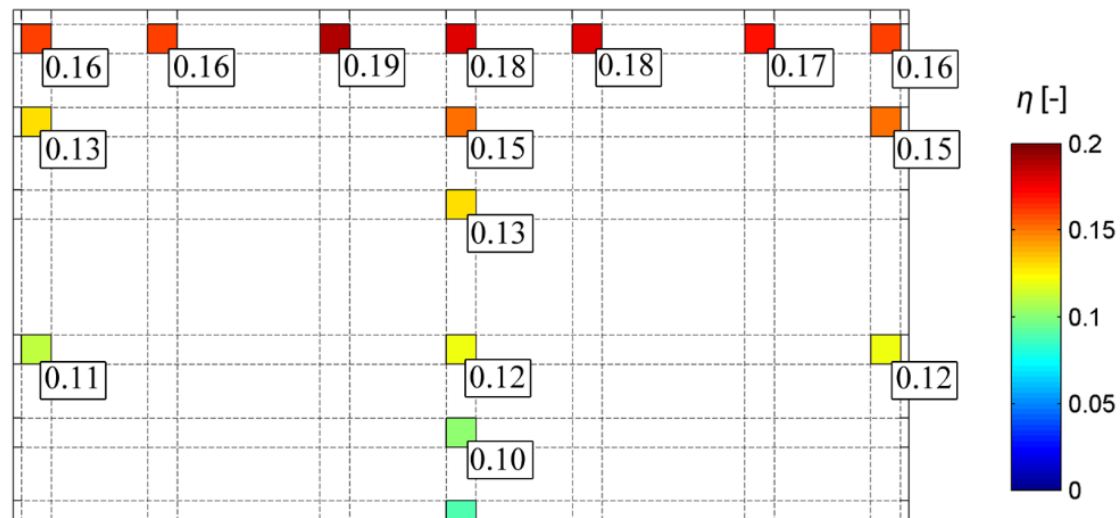

b)
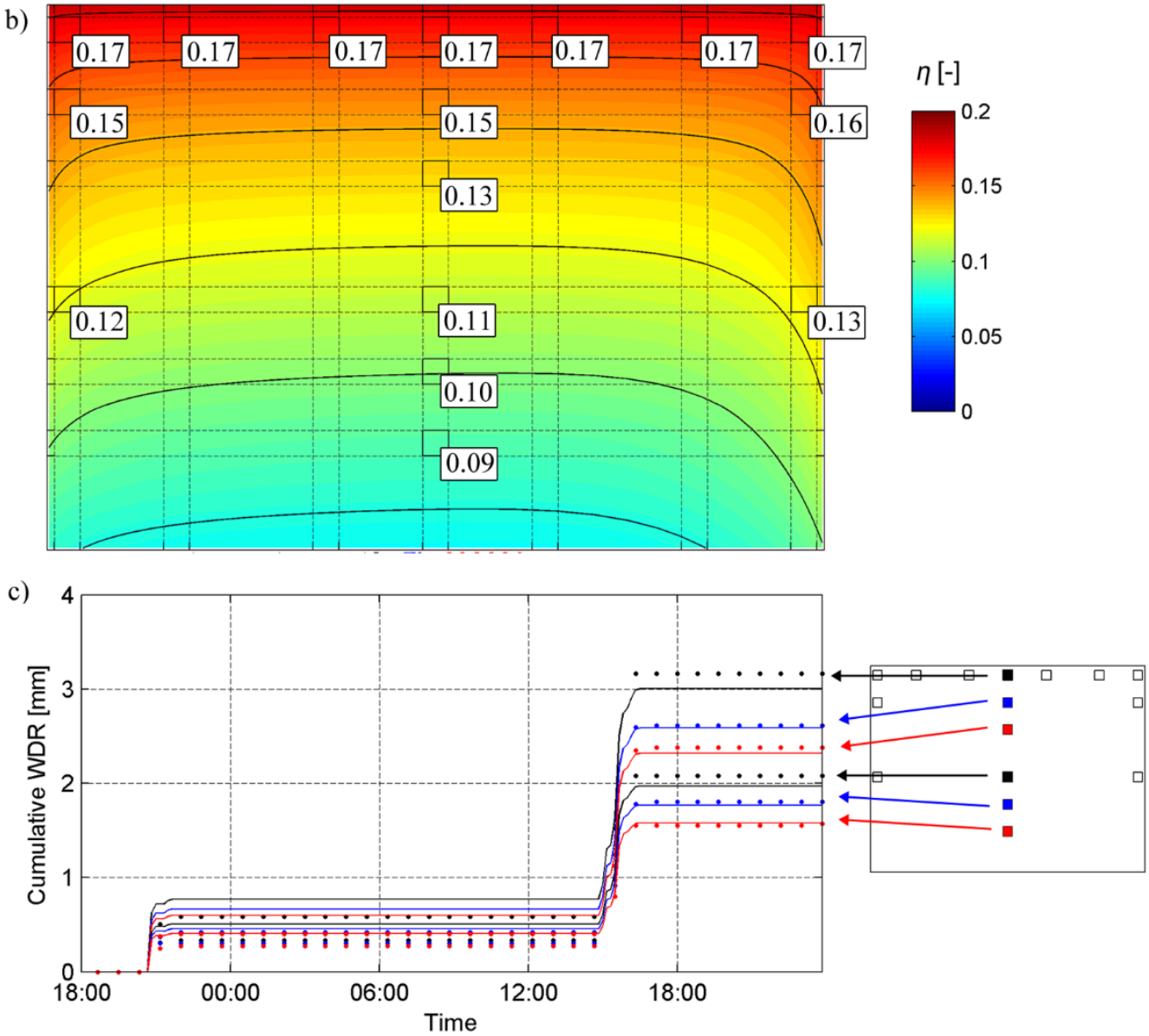

Fig. 12. Comparison of a) experimental and b) numerical catch ratio data on the west facade of building 2 after the rain event on August 2-3, 2014. c) Comparison of experimental (dots) and numerical (lines) cumulative WDR amounts on building 2 during the rain event on August 2-3, 2014. 

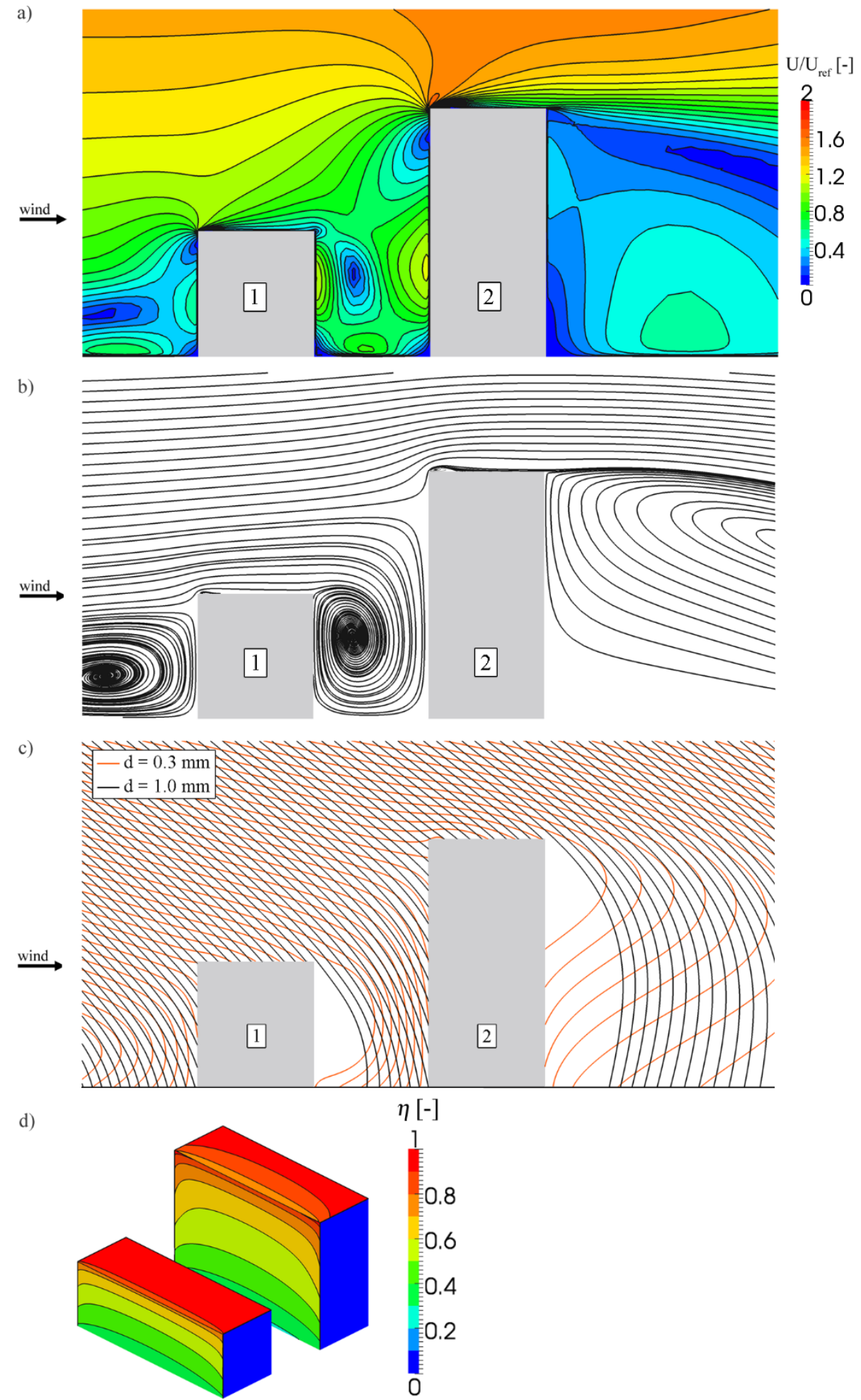

Fig. 13. a) Contours and b) streamlines of normalized wind speed and c) streamlines of rain phases for raindrop sizes $d=0.3$ and $1.0 \mathrm{~mm}$ at reference wind speed $U=3 \mathrm{~m} / \mathrm{s}$ in the vertical centerplane for wind from west. d) Catch ratio distribution at reference wind speed $U=3 \mathrm{~m} / \mathrm{s}$ and reference rainfall intensity $R_{h}=1 \mathrm{~mm} / \mathrm{h}$ for wind from west. 
a) Case 1

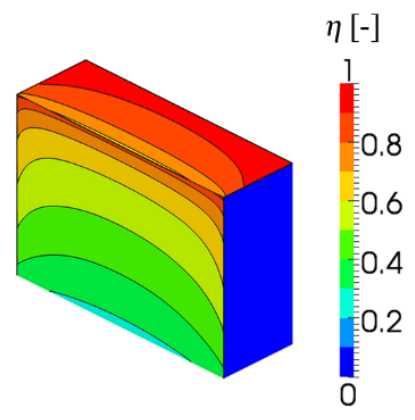

b) Case 2

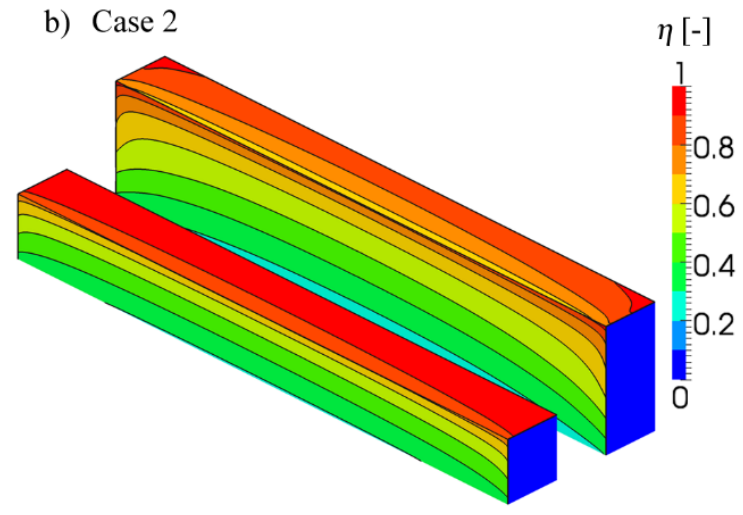

c) Case 3

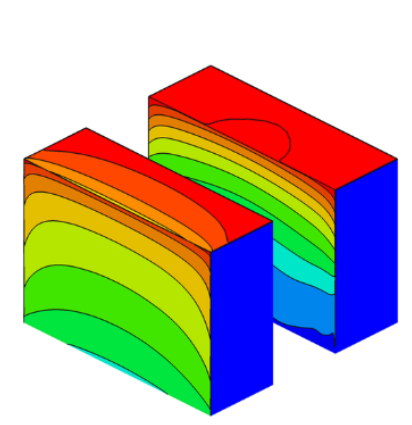

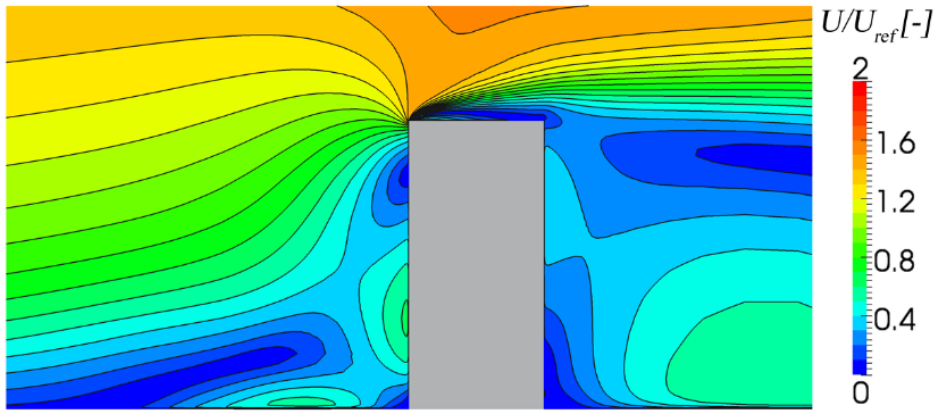
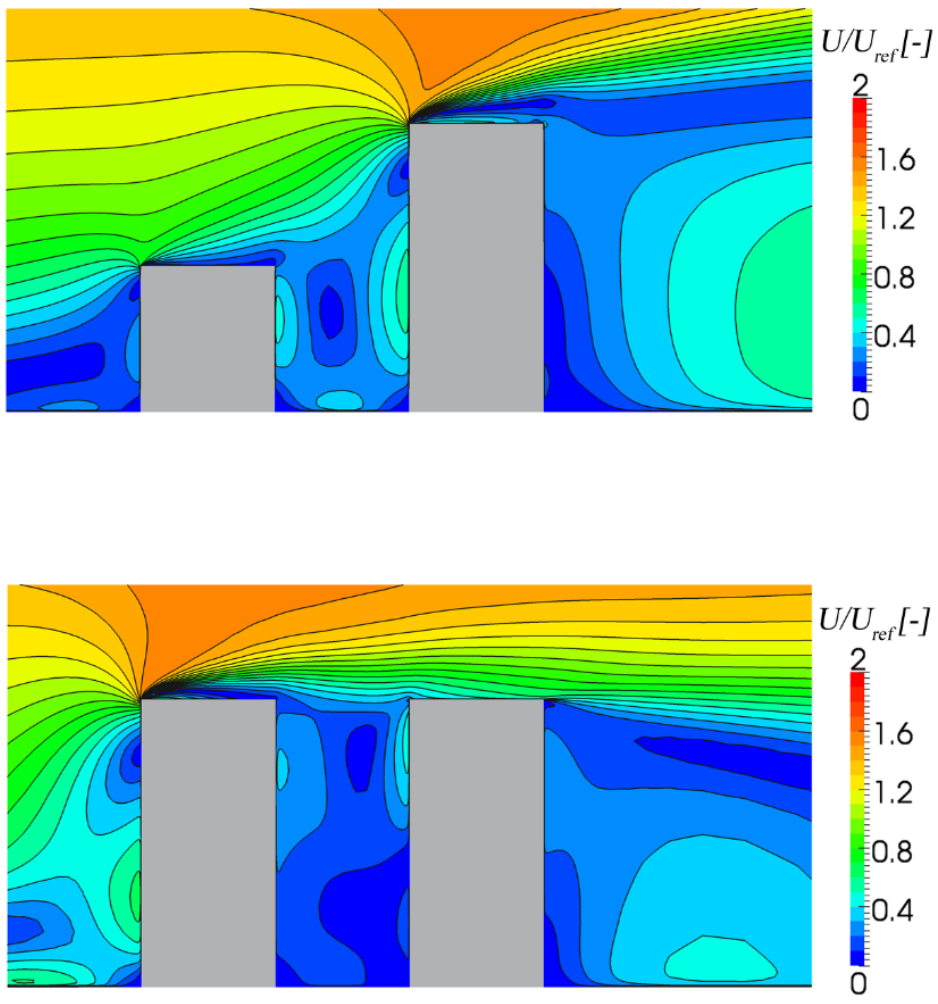

Fig. 14. Catch ratio distributions at reference wind speed $U=3 \mathrm{~m} / \mathrm{s}$ and reference rainfall intensity $R_{h}=1 \mathrm{~mm} / \mathrm{h}$ and contours of normalized wind speed in the vertical centerplane for wind from west for cases a) 1, b) 2 and c) 3 . 

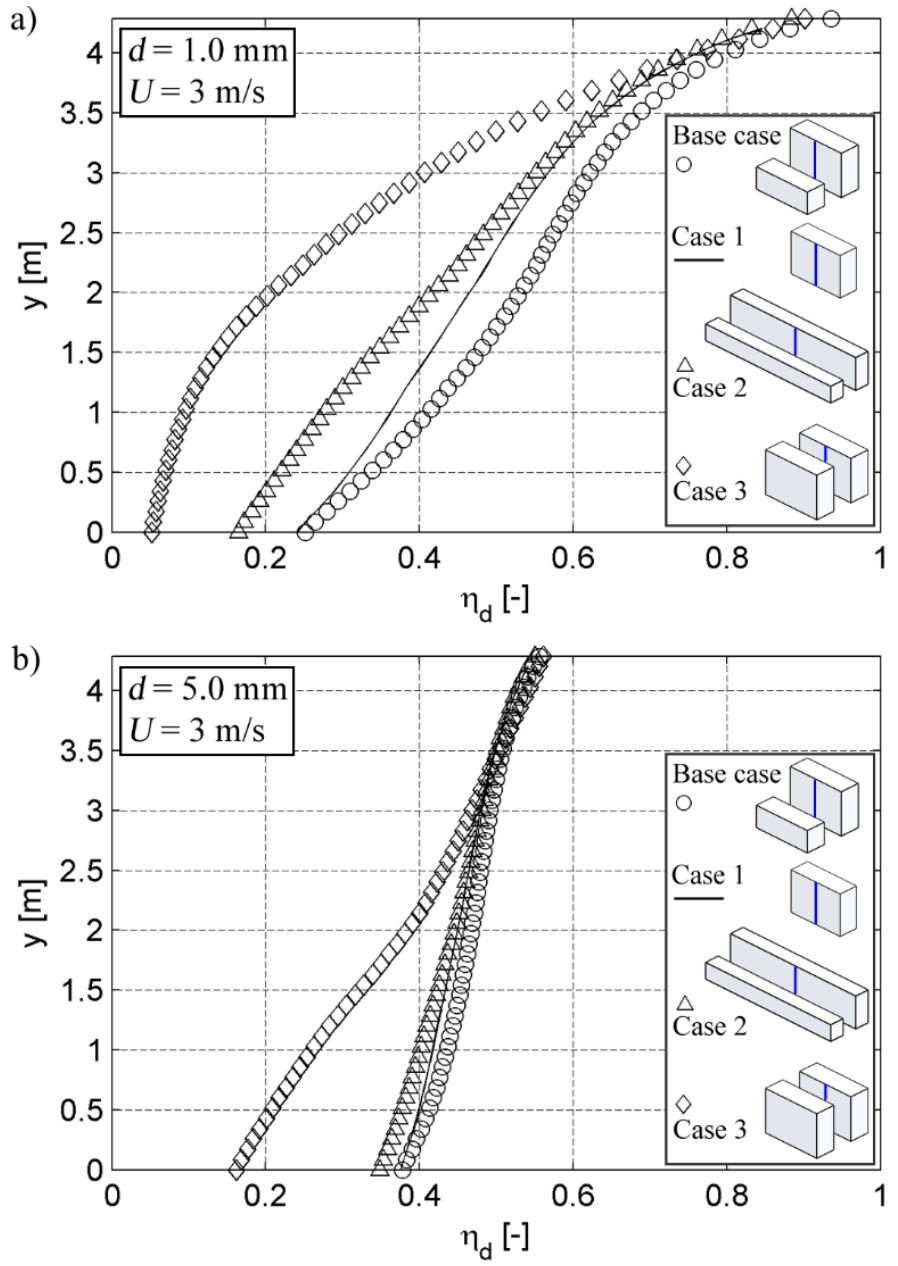

Fig. 15. Comparison of specific catch ratio values along a vertical line in the middle of the facades of the downstream buildings for raindrop diameters a) 1.0 and b) $5.0 \mathrm{~mm}$ for wind from west at a reference wind speed of $3 \mathrm{~m} / \mathrm{s}$. 


\section{Tables}

Table 1. Calibration information for WDR gauges on building 1 .

\begin{tabular}{lll}
\hline WDR gauge & 1 & 2 \\
\hline $\begin{array}{l}\text { Bucket } \\
\text { volume [ml] }\end{array}$ & 0.955 & 0.969 \\
$\begin{array}{l}\text { Resolution } \\
{[\mathrm{mm} / \mathrm{tip}]}\end{array}$ & 0.024 & 0.024 \\
\hline
\end{tabular}

Table 2. Calibration information for WDR gauges on building 2.

\begin{tabular}{lllllllll}
\hline $\begin{array}{l}\text { WDR } \\
\text { gauge }\end{array}$ & 1 & 2 & 3 & 4 & 5 & 6 & 7 & 8 \\
\hline $\begin{array}{l}\text { Bucket } \\
\text { volume } \\
{[\mathrm{ml}]}\end{array}$ & 0.961 & 1.018 & 0.956 & 1.128 & 1.052 & 1.013 & 0.934 & 1.069 \\
$\begin{array}{l}\text { Resolution } \\
\text { [mm/tip] }\end{array}$ & 0.024 & 0.025 & 0.024 & 0.028 & 0.026 & 0.025 & 0.023 & 0.027 \\
\hline $\begin{array}{l}\text { WDR } \\
\text { gauge }\end{array}$ & 9 & 10 & 11 & 12 & 13 & 14 & 15 & 16 \\
\hline $\begin{array}{l}\text { Bucket } \\
\text { volume }\end{array}$ & 1.028 & 1.016 & 0.912 & 1.128 & 0.967 & 1.133 & 0.976 & 1.090 \\
$\begin{array}{l}\text { [ml }] \\
\begin{array}{l}\text { Resolution } \\
{[\mathrm{mm} / \text { tip }]}\end{array}\end{array}$ & 0.026 & 0.025 & 0.023 & 0.028 & 0.024 & 0.028 & 0.024 & 0.027 \\
\hline
\end{tabular}

Table 3. Rain registration data and error estimates for the wind-driven rain measurements for the rain event on February 20-21, 2014 on building 1.

\begin{tabular}{llllll}
\hline $\begin{array}{l}\text { WDR } \\
\text { gauge }\end{array}$ & $\begin{array}{l}\text { Number } \\
\text { of tips }\end{array}$ & $\begin{array}{l}\mathrm{S}_{\mathrm{wdr}} \\
{[\mathrm{mm}]}\end{array}$ & $\begin{array}{l}\mathrm{E}_{\mathrm{AW}} \\
{[\mathrm{mm}]}\end{array}$ & $\begin{array}{l}\mathrm{E}_{\mathrm{RW}} \\
{[\mathrm{mm}]}\end{array}$ & $\begin{array}{l}\mathrm{E}_{\mathrm{TOT}} \\
(\%)\end{array}$ \\
\hline 1 & 72 & 1.72 & 0.375 & 0.072 & 26.0 \\
2 & 57 & 1.38 & 0.375 & 0.000 & 27.2 \\
\hline
\end{tabular}

Table 4. Rain registration data and error estimates for the wind-driven rain measurements for the rain event on February 20-21, 2014 on building 2.

\begin{tabular}{llllllllllll}
\hline $\begin{array}{l}\text { WDR } \\
\text { gauge }\end{array}$ & $\begin{array}{l}\text { Number } \\
\text { of tips }\end{array}$ & $\begin{array}{l}\mathrm{S}_{\mathrm{wdr}} \\
{[\mathrm{mm}]}\end{array}$ & $\begin{array}{l}\mathrm{E}_{\mathrm{AW}} \\
{[\mathrm{mm}]}\end{array}$ & $\begin{array}{l}\mathrm{E}_{\mathrm{RW}} \\
{[\mathrm{mm}]}\end{array}$ & $\begin{array}{l}\mathrm{E}_{\mathrm{TOT}} \\
(\%)\end{array}$ & $\begin{array}{l}\text { WDR } \\
\text { gauge }\end{array}$ & $\begin{array}{l}\text { Number } \\
\text { of tips }\end{array}$ & $\begin{array}{l}\mathrm{S}_{\mathrm{wdr}} \\
{[\mathrm{mm}]}\end{array}$ & $\begin{array}{l}\mathrm{E}_{\mathrm{AW}} \\
{[\mathrm{mm}]}\end{array}$ & $\begin{array}{l}\mathrm{E}_{\mathrm{RW}} \\
{[\mathrm{mm}]}\end{array}$ & $\begin{array}{l}\mathrm{E}_{\mathrm{TOT}} \\
(\%)\end{array}$ \\
\hline 1 & 84 & 2.02 & 0.375 & 0.075 & 22.3 & 9 & 50 & 1.29 & 0.375 & 0.075 & 35.0 \\
2 & 65 & 1.65 & 0.375 & 0.072 & 27.0 & 10 & 32 & 0.81 & 0.375 & 0.069 & 54.6 \\
3 & 55 & 1.31 & 0.375 & 0.084 & 34.9 & 11 & 37 & 0.84 & 0.375 & 0.084 & 54.4 \\
4 & 73 & 2.06 & 0.375 & 0.078 & 22.0 & 12 & 81 & 2.28 & 0.375 & 0.072 & 19.6 \\
5 & 83 & 2.18 & 0.375 & 0.075 & 20.6 & 13 & 80 & 1.93 & 0.375 & 0.084 & 23.7 \\
6 & 85 & 2.15 & 0.375 & 0.069 & 20.6 & 14 & 76 & 2.15 & 0.375 & 0.072 & 20.8 \\
7 & 73 & 1.70 & 0.375 & 0.081 & 26.8 & 15 & 62 & 1.51 & 0.375 & 0.081 & 30.1 \\
8 & 56 & 1.50 & 0.375 & 0.078 & 30.3 & 16 & 46 & 1.25 & 0.375 & 0.000 & 29.9 \\
\hline
\end{tabular}


Table 5. Rain registration data and error estimates for the wind-driven rain measurements for the rain event on August 2-3, 2014 on building 1.

\begin{tabular}{clllll}
\hline $\begin{array}{c}\text { WDR } \\
\text { gauge }\end{array}$ & $\begin{array}{l}\text { Number } \\
\text { of tips }\end{array}$ & $\begin{array}{l}\mathrm{S}_{\mathrm{wdr}} \\
{[\mathrm{mm}]}\end{array}$ & $\begin{array}{l}\mathrm{E}_{\mathrm{AW}} \\
{[\mathrm{mm}]}\end{array}$ & $\begin{array}{l}\mathrm{E}_{\mathrm{RW}} \\
{[\mathrm{mm}]}\end{array}$ & $\begin{array}{l}\mathrm{E}_{\mathrm{TOT}} \\
(\%)\end{array}$ \\
\hline 1 & 102 & 2.44 & 0.250 & 0.048 & 12.2 \\
2 & 88 & 2.13 & 0.250 & 0.048 & 14.0 \\
\hline
\end{tabular}

Table 6. Rain registration data and error estimates for the wind-driven rain measurements for the rain event on August 2-3, 2014 on building 2 .

\begin{tabular}{clllllllllll}
\hline $\begin{array}{l}\text { WDR } \\
\text { gauge }\end{array}$ & $\begin{array}{l}\text { Number } \\
\text { of tips }\end{array}$ & $\begin{array}{l}\mathrm{S}_{\mathrm{wdr}} \\
{[\mathrm{mm}]}\end{array}$ & $\begin{array}{l}\mathrm{E}_{\mathrm{AW}} \\
{[\mathrm{mm}]}\end{array}$ & $\begin{array}{l}\mathrm{E}_{\mathrm{RW}} \\
{[\mathrm{mm}]}\end{array}$ & $\begin{array}{l}\mathrm{E}_{\mathrm{TOT}} \\
(\%)\end{array}$ & $\begin{array}{l}\text { WDR } \\
\text { gauge }\end{array}$ & $\begin{array}{l}\text { Number } \\
\text { of tips }\end{array}$ & $\begin{array}{l}\mathrm{S}_{\mathrm{wdr}} \\
{[\mathrm{mm}]}\end{array}$ & $\begin{array}{l}\mathrm{E}_{\mathrm{AW}} \\
{[\mathrm{mm}]}\end{array}$ & $\begin{array}{l}\mathrm{E}_{\mathrm{RW}} \\
{[\mathrm{mm}]}\end{array}$ & $\begin{array}{l}\mathrm{E}_{\mathrm{TOT}} \\
(\%)\end{array}$ \\
\hline 1 & 118 & 2.84 & 0.250 & 0.048 & 10.5 & 9 & 81 & 2.08 & 0.250 & 0.052 & 14.5 \\
2 & 107 & 2.72 & 0.250 & 0.050 & 11.0 & 10 & 71 & 1.80 & 0.250 & 0.050 & 16.6 \\
3 & 88 & 2.10 & 0.250 & 0.048 & 14.2 & 11 & 69 & 1.57 & 0.250 & 0.046 & 18.8 \\
4 & 104 & 2.93 & 0.250 & 0.056 & 10.4 & 12 & 118 & 3.33 & 0.250 & 0.056 & 9.2 \\
5 & 122 & 3.21 & 0.250 & 0.052 & 9.4 & 13 & 114 & 2.76 & 0.250 & 0.048 & 10.8 \\
6 & 125 & 3.17 & 0.250 & 0.050 & 9.5 & 14 & 97 & 2.75 & 0.250 & 0.056 & 11.1 \\
7 & 112 & 2.62 & 0.250 & 0.046 & 11.3 & 15 & 91 & 2.22 & 0.250 & 0.048 & 13.4 \\
8 & 89 & 2.38 & 0.250 & 0.054 & 12.8 & 16 & 69 & 1.88 & 0.250 & 0.054 & 16.2 \\
\hline
\end{tabular}

